\title{
Bacteria Associated with Russian Wheat Aphid (Diuraphis noxia) Enhance Aphid Virulence to Wheat
}

Emily Luna, Department of Bioagricultural Sciences and Pest Management, Colorado State University, Fort Collins 80523-1177; Leon van Eck, Department of Soil and Crop Sciences, Colorado State University, Fort Collins 80523, and Biology Department, Augsburg University, Minneapolis, MN 55454; Tony Campillo, Department of Bioagricultural Sciences and Pest Management, Colorado State University, Fort Collins 80523-1177; Margaret Weinroth and Jessica Metcalf, Department of Animal Sciences, Colorado State University, Fort Collins 80523; Alvaro L. Perez-Quintero, Department of Bioagricultural Sciences and Pest Management, Colorado State University, Fort Collins 80523-1177; Anna-Maria Botha, Department of Genetics, Stellenbosch University, Stellenbosch 7600, South Africa; Theodore W. Thannhauser, Robert W. Holley Center for Agriculture and Health, USDA-ARS, Ithaca, NY 14853; Darryl Pappin, Cold Spring Harbor Laboratory, Cold Spring Harbor, NY 11724; Ned A. Tisserat, Department of Bioagricultural Sciences and Pest Management, Colorado State University, Fort Collins 80523-1177; Nora L. V. Lapitan, United States Agency for International Development, Washington, DC 20523; Cristiana T. Argueso and Paul J. Ode, Department of Bioagricultural Sciences and Pest Management, Colorado State University, Fort Collins 80523-1177; Michelle L. Heck, Robert W. Holley Center for Agriculture and Health, USDA-ARS, Ithaca, NY 14853, and Plant Pathology and Plant-Microbe Biology Section, School of Integrative Plant Science, Cornell University, Ithaca, NY 14853; and Jan E. Leach, ${ }^{\dagger}$ Department of Bioagricultural Sciences and Pest Management, Colorado State University, Fort Collins 80523-1177

Accepted for publication 13 August 2018.

\section{ABSTRACT}

Phenotypic responses to biotic stresses are often studied as the interactions between two species; however, in the phytobiome, these responses frequently result from complex interactions involving several organisms. Here, we show that variation in chlorosis caused by Russian wheat aphid (Diuraphis noxia) feeding is determined, in part, by aphid-associated bacteria. Proteomic analysis of fluids injected into a sterile medium by the aphid during feeding indicate that $99 \%$ of the proteins are of bacterial origin. Of these, the greatest proportion are produced by bacteria in the order Enterobacteriales. Bacteria from five genera in four families that have the capacity to produce these proteins were isolated directly from aphids as well as from wheat leaves only after $D$. noxia feeding. By themselves or in combination, these bacteria were not virulent to wheat, even at high inoculum levels. Metagenomic analysis showed that the same five
D. noxia-associated genera dominated the non-Buchnera component of the aphid microbiome, and that representation of these genera was reduced in aphids from colonies established after isolation of newborn nymphs from their mothers prior to feeding (isolated aphids). Isolation or treatment with antibiotics reduced bacterial numbers, and these aphids caused less feeding damage on wheat than non-isolated or non-antibiotic-treated aphids. Our data show that bacterial proteins are a significant component of Russian wheat aphid saliva, that the bacteria producing these proteins are associated with aphids and plants fed upon by aphids, and that these aphid-associated bacteria facilitate aphid virulence to wheat.

Additional keywords: aphid saliva, Enterobacteriaceae, microbiome, multitrophic interactions, phytobiome, proteome.
${ }^{\dagger}$ Corresponding author: J. E. Leach; E-mail: Jan.Leach@colostate.edu

Funding: This work was supported with funding from the Colorado Wheat Research Foundation, the Colorado State University Agricultural Experiment Station, the National Science Foundation Grant 1354309, and USDA-ARS CRIS Project number 8062-22000-021-00-D.

*The $\boldsymbol{e}$-Xtra logo stands for "electronic extra" and indicates that seven supplementary figures, five supplementary tables, and one supplementary dataset are published online.

(C) 2018 The American Phytopathological Society
Aphids have intimate associations with various bacteria. These associations range from mutualistic to pathogenic (Buchner 1965) and are classified as either obligate or facultative (Gil et al. 2004). The obligate endosymbiont Buchnera aphidicola is essential for aphids because it synthesizes several amino acids that plant sap lacks (Douglas and Prosser 1992), an association which was established over 180 million years ago (Moran et al. 1993). Other nonobligatory secondary endosymbionts, such as 'Candidatus Hamiltonella defensa', 'Ca. Serratia symbiotica', ' $C a$. Regiella insecticola', and 
Rickettsia spp. are not required for aphid survival but enable aphids to defend themselves against natural enemies (parasitoids, fungi, or bacteria) or promote high temperature tolerance (Montllor et al. 2002; Oliver et al. 2003; Scarborough et al. 2005). Besides endosymbiotic bacteria, aphids carry other bacteria that have not received as much attention. Facultative bacteria such as Erwinia spp., Pantoea spp., Dickeya dadantii, and Pseudomonas syringae are carried by, or may be ingested by aphids, and may replicate within the aphids (Campillo et al. 2015; Correa et al. 2012; Costechareyre et al. 2012; Harada et al. 1997; Stavrinides et al. 2009, 2010). In contrast to obligate symbionts that are transmitted vertically (Douglas 1998), these associated bacteria are usually horizontally transmitted (Oliver et al. 2010, 2012). In recent years, several studies have characterized all of the bacteria present in aphid samples by deep sequencing of 16S rRNA gene sequences (Bansal et al. 2014; Gauthier et al. 2015; Gil et al. 2004; Jing et al. 2014; Jones et al. 2011; Jousselin et al. 2016). A common theme throughout these studies is the reduced abundance of facultative bacteria relative to the primary and secondary endosymbionts.

Aphids are piercing-sucking insects that use a stylet to probe intercellularly through the mesophyll until reaching the phloem sap, where feeding begins (Miles 1999). During probing and feeding, aphids secrete saliva into the plant, and the saliva is thought to suppress plant defense responses (Miles 1999). Many studies have characterized the salivary proteome of aphids in search of candidate virulence proteins (effectors) (Bos et al. 2010; Carolan et al. 2011; Cooper et al. 2010; Harmel et al. 2008; Mugford et al. 2016; Nicholson and Puterka 2014; Nicholson et al. 2012; Vandermoten et al. 2014). Several aphid proteins were proposed to be effectors from these studies, but only one of these aphid proteins was shown to be an effector (Mugford et al. 2016). Evidence is lacking for effectors in other aphid species, notably the agricultural pest Russian wheat aphid, Diuraphis noxia (Kurdjumov) (Hemiptera: Aphididae). Although a few studies have characterized the salivary proteome of D. noxia, no study to date identified candidate aphid-produced virulence proteins (Cooper et al. 2010; Nicholson et al. 2012). Similarly, genome characterizations of $D$. noxia revealed no candidate effectors (Burger and Botha 2017; Nicholson et al. 2015).

Russian wheat aphid is particularly damaging to wheat (Triticum aestivum L.) and barley (Hordeum vulgare L.). Symptoms of aphid feeding include leaf chlorosis, plant stunting, leaf rolling, and plant desiccation, and these ultimately lead to yield reduction (Burger et al. 2017; Webster et al. 1987; Zwer et al. 1994). Resistant cultivars are employed for aphid management, however, aphids quickly overcome plant resistance by evolving new biotypes. Assignment of these biotypes is based on differential virulence to wheat (i.e., D. noxia biotype 1 is less virulent than biotype 2) (Nicholson et al. 2012).

The abundance, diversity, and role of facultative bacteria colonizing aphid species is still relatively unknown and likewise, attempts at characterizing the aphid-associated bacterial composition of D. noxia are scant (Anathakrishnan et al. 2014; Campillo et al. 2015). In one study, a gut transcriptomic analysis for D. noxia found higher bacterial sequence diversity in Russian wheat aphid biotype 2 relative to biotype 1 (Anathakrishnan et al. 2014). In our previous study, we isolated several bacterial genera and identified the aphidassociated bacterium Erwinia iniecta (Campillo et al. 2015). Other than these studies, no information is available on facultative bacteria associated with Russian wheat aphid or their role in aphid feeding and establishment.

In this study, we characterized the proteome of $D$. noxia saliva and showed that few aphid salivary proteins were present, but instead, many proteins of bacterial origin, predominantly from three genera in Enterobacteriales were detected. Bacteria from these same genera were isolated from artificial diets and from wheat plants, but only those that were fed upon by $D$. noxia. We show that $D$. noxia with reduced bacterial populations cause less chlorosis in wheat, and that the microbiomes of these bacterial-deficient aphids are underrepresented in many of the same bacterial genera detected in aphid saliva. Based on these findings, we hypothesize that D. noxia delivers bacteria to the plant during feeding and that these bacteria enhance aphid virulence.

\section{MATERIALS AND METHODS}

Plant growth and aphid rearing. Parthenogenic colonies of D. noxia biotypes 1 and 2, originally collected from field infestations of wheat in $\mathrm{CO}$, were reared and maintained on susceptible wheat plants (Triticum aestivum L.) cultivars TAM 107, Yuma, and Byrd following the methods described in Randolph et al. (2009). Wheat plants susceptible to both aphid biotypes 1 and 2 , were grown in a greenhouse with $16 \mathrm{~h}$ light $/ 8 \mathrm{~h}$ dark at $23 \pm 3^{\circ} \mathrm{C}$, in Promix soil (Premier Horticulture, Dorval, QC, Canada). The infested plants were held in $60 \times 60 \times 60 \mathrm{~cm}$ insect cages (Bug Dorm Store, Megaview Inc., Taichung, Taiwan) to avoid contamination with nonexperimental aphid species.

Aphid saliva collection. Russian wheat aphid biotypes 1 and 2 were reared on susceptible wheat cultivar TAM 107 for several generations prior to the start of the experiment. Saliva collection plates were constructed per Cooper et al. (2010). Briefly, the plates were constructed under sterile conditions by stretching a thin membrane of Parafilm (Pechiney Plastic Packaging, Chicago, IL) over an inverted $60 \times 15 \mathrm{~mm}$ Petri dish. Before sealing with Parafilm, $1.2 \mathrm{ml}$ of sterile sucrose solution (15\%, $\mathrm{pH} 7.2$ ) was added, forming a feeding sachet. A 50-mm O-ring was placed on top of the Parafilm and $\sim 500$ apterous adult aphids were then placed on each plate. Aphids were incubated at $22^{\circ} \mathrm{C}$ under a yellow light at a $14 \mathrm{~h}$ light/10 $\mathrm{h}$ dark photoperiod as described (Cooper et al. 2010). The entire experiment was replicated three times with 130 cages constructed per biotype (130 cages $\times 2$ biotypes $\times 3$ replicates $=780$ cages total). Collection plates incubated without aphids served as controls. After $48 \mathrm{~h}$ of feeding, aphids were removed with a paintbrush, and the surface of the feeding sachet was rinsed with sterile distilled water. For protein analysis, the diet was collected by making an incision in the Parafilm at the edge of the dish, rinsing the underside of the Parafilm by pipetting the diet up and down a few times to ensure the collection of any adhering proteins, and finally removing the diet with the pipette. This entire sample was collected into $50-\mathrm{ml}$ centrifuge tubes and the proteins were precipitated from the artificial diet by the addition of $10 \%$ trichloroacetic acid, $60 \%$ acetone, $1 \% \beta$-mercaptoethanol (final concentrations) and incubating the samples at $-20^{\circ} \mathrm{C}$ overnight. Precipitated proteins were collected by centrifuging at $5,000 \times \mathrm{g}$ for $30 \mathrm{~min}$ at $4{ }^{\circ} \mathrm{C}$ and removing the supernatant. The walls of each $50-\mathrm{ml}$ tube were washed extensively with ice-cold acetone to remove residual sucrose and the sample was pelleted by centrifugation at $7,000 \times g$ for $10 \mathrm{~min}$ at $4^{\circ} \mathrm{C}$. Samples were dried using a vacuum concentrator prior to solubilization in the appropriate solutions for downstream analysis.

iTRAQ analysis. Three biological replicates were analyzed for each of the two aphid biotypes. Each biological replicate was comprised of pools of saliva collected from thousands of individual insects from three clonal lineages of each $D$. noxia biotype. Protein pellets were solubilized in $0.1 \%$ ProteaseMax (PMAX) surfactant (Promega), $50 \mathrm{mM}$ triethylammonium bicarbonate (TEAB), and total protein concentrations were estimated using a Quick Start Bradford Protein Assay (Bio-Rad, Hercules, CA). The integrity of the protein samples was assessed by separation and visualization in 
$10 \%$ SDS-gels as described (Ramsey et al. 2015). Samples were each aliquoted at $1 \mu \mathrm{g} \mu \mathrm{l}^{-1}$ starting protein in a total volume of $65 \mu \mathrm{l}$.

For reduction and cysteine blocking steps, $50 \mathrm{mM}$ TEAB and $0.1 \%$ PMAX was added to the solution. Samples were reduced with $5 \mathrm{mM}$ tris-(2-carboxyethyl)-phosphine (TCEP, pH 8.5) for $20 \mathrm{~min}$ at $55^{\circ} \mathrm{C}$, and $10 \mathrm{mM}$ methyl-methane-thiosulfonate (MMTS) was added to each sample and incubated for $20 \mathrm{~min}$ at room temperature. A methanol/chloroform precipitation was carried out at $4{ }^{\circ} \mathrm{C}$ for 75 min after adding the following to each sample: $4 \times$ volume methanol, $1 \times$ volume chloroform, and $3 \times$ volume deionized water. After centrifugation $\left(15,000 \times g\right.$ for $5 \mathrm{~min}$ at $\left.4^{\circ} \mathrm{C}\right)$ and removal of the supernatant, methanol was added to each pellet at $3 \times$ the sample volume, and the pellets were gently vortexed followed by centrifugation at $4^{\circ} \mathrm{C}$ for $5 \mathrm{~min}$. The methanol was removed, and the pellet was air dried briefly. The pellets were solubilized in $0.1 \%$ PMAX/ $50 \mathrm{mM}$ TEAB. Sequence grade modified trypsin ( $1 \mu \mathrm{g} / \mathrm{sample})$ was added and samples were incubated overnight at $37^{\circ} \mathrm{C}$. The digested samples were subjected to vacuum centrifugation until almost dry, and then $30 \mu \mathrm{l}$ of $500 \mathrm{mM}$ TEAB was added to each. The iTRAQ labeling reagents (Applied Biosystems, Foster City, CA) were each reconstituted in $50 \mu \mathrm{l}$ of isopropanol and added to each sample as directed by the manufacturer. The samples were incubated at room temperature for $2 \mathrm{~h}$ during the labeling reaction. TFA was added to each sample to bring the $\mathrm{pH}$ below 4 . All six biological replicates labeled with individual iTRAQ reporter mass tags were then pooled to one single tube and mixed for analysis.

Combined, iTRAQ-labeled samples were analyzed using twodimensional liquid chromatography MudPIT(Washburn 2004), using a two-dimensional vented column setup with a Proxeon nanoflow high-performance liquid pump (Taylor et al. 2009). A total of $50 \mu \mathrm{g}$ of sample was loaded onto a triphasic, fused silica capillary column: $250 \mu \mathrm{m}$ internal diameter packed with $3 \mathrm{~cm}$ of $5 \mu \mathrm{m}$ Aqua C18, followed by $3 \mathrm{~cm}$ of $5 \mu \mathrm{m}$ Luna SCX and $2 \mathrm{~cm}$ of $5 \mu \mathrm{m}$ Aqua C18. A total of seven salt steps were used. For each salt step, peptides were eluted on an analytical column of a $100 \mu \mathrm{m}$ internal diameter capillary with a $5 \mu \mathrm{m}$ pulled tip and packed with $15 \mathrm{~cm}$ of $3 \mu \mathrm{m}$ Aqua C18 on line with an LTQ Orbitrap Velos (Thermo Fisher) as described in (Scuoppo et al. 2012). Data were acquired in profile mode using the following parameters: for full-scan Fourier transform mass spectrometry, resolution $=60,000, \mathrm{~m} / \mathrm{z}=380$ to 1,700 and the 10 most intense ions were fragmented with highercollision dissociation at a normalized collision energy of $40 \%$ and an activation time of 0.1 . Minimum threshold signal was at 5,000 and isolation width at 1.2. Dynamic exclusion settings were repeat count 1 , repeat duration of 30 , exclusion list size 500, exclusion duration 60 and exclusion mass width $10 \mathrm{ppm}$. All mass spectrometry data files associated with this experiment can be found on ProteomeXChange, (Project accession PXD010663).

Protein identification. The MS and MS/MS data collected were submitted to Mascot v.2.3 (Matrix Science, Boston, MA) using an in-house MASCOT server for database interrogation. The data were searched against the entire NCBI nonredundant database, which contained the A. pisum gene models (download date: January 2011). This initial search revealed that the samples were comprised predominantly of proteins associated with plant pathogenic bacteria. Therefore, we also searched the data using a custom database that contained a combination of predicted proteins from A. pisum (from NCBI, download date 7-23-2014), sequences from common contaminant proteins, as well as prokaryotic proteins predicted from microbes known to be associated with aphids, including Erwinia spp., Pantoea spp., Enterobacter spp., Acinetobacter spp., and insect endosymbionts belonging either to the order Enterobacteriales (Photorhabdus spp., 'Candidatus Hamiltonella defensa', 'Candidatus
Regiella insecticola', Arsenophonus spp., B. aphidicola, 'Candidatus Carsonella ruddii' and Serratia symbiotica) or Rickettsiales (Wolbachia spp. and Rickettsia spp.). The latter custom database had a total of 2,033,158 sequences. The following search parameters were used: methylthio-cysteine as a fixed modification, methionine oxidation as a variable modification, and one missed tryptic cleavage. The searches were done with a mass error tolerance of $25 \mathrm{ppm}$ for precursor ions and $0.1 \mathrm{Da}$ for fragment ions. As described in the Scaffold Q+ (version Scaffold_4.4.1.1, Proteome Software Inc., Portland, OR) Publication Report, iTRAQ peptide and protein identifications were quantified as follows. Peptide identifications were accepted if they could be established at greater than $95.0 \%$ probability by the Scaffold local false discovery rate algorithm. Protein identifications were accepted if they could be established at greater than $95.0 \%$ probability and contained at least two identified peptides. Protein probabilities were assigned by the Protein Prophet algorithm (Nesvizhskii et al. 2003). Proteins that contained similar peptides and could not be differentiated based on MS/MS analysis alone were grouped to satisfy the principles of parsimony. Proteins sharing significant peptide evidence were grouped into clusters. Channels were corrected according to the algorithm described in i-Tracker (Shadforth et al. 2005) as follows. Acquired intensities in the experiment were globally normalized across all acquisition runs. Individual quantitative samples were normalized within each acquisition run. Intensities for each peptide identification were normalized within the assigned protein. The reference channels were normalized to produce a 1:onefold change. All normalization calculations were performed using medians to multiplicatively normalize data.

Bacterial isolation and characterization. Bacteria were isolated from $D$. noxia biotype 1 and 2 bodies and artificial diets as previously described (Campillo et al. 2015). Sterile artificial diets handled in the same way, but not exposed to aphids, served as a control. To isolate bacteria from plant material, 24 aphids were placed on 14-day-old wheat leaves. After 2 weeks, the aphids were gently removed from the leaf surface with a paintbrush and leaf samples were taken from the symptomatic portion of five different leaves. Samples were treated with $10 \%$ bleach for $10 \mathrm{~s}$, rinsed with sterile water, and then ground in $100 \mu \mathrm{l}$ of distilled water using a sterile glass rod. Leaves that had not been exposed to aphids served as controls. Isolation experiments were performed twice, with four replications per experiment. Suspensions from all of the above sources were plated on Eosin Methylene Blue agar (HoltHarris and Teague 1916) or nutrient agar medium and incubated $72 \mathrm{~h}$ at $28^{\circ} \mathrm{C}$. Single colonies were selected and streaked onto a new agar plate. This step was performed at least three times to obtain pure bacterial cultures.

To determine the rrs gene (encoding $16 \mathrm{~S}$ small ribosomal subunit) sequence for phylogenetic purposes, bacterial genomic DNA was extracted using an Easy DNA kit (Invitrogen, CA) per the manufacturer's instructions. Gene amplifications were performed by polymerase chain reactions (PCR) containing $5 \times$ PCR Phusion HF buffer (Finnzymes, Finland), $0.2 \mathrm{mM}$ dNTP, $0.5 \mathrm{mM}$ forward (FD1, 5' -agagtttgatcctggctcag-3') and reverse (RP2, 5' -acggcta ccttgttacgactt-3') primers (Weisburg et al. 1991), $25 \mathrm{ng}$ of extracted genomic DNA, 3\% DMSO, and 0.5 unit of Phusion Taq polymerase (Finnzymes, Finland) in $20 \mu \mathrm{l}$ of aqueous solution. An initial denaturation step was performed at $98^{\circ} \mathrm{C}$ for $1 \mathrm{~min}$ followed by 35 cycles: $10 \mathrm{~s}$ at $98^{\circ} \mathrm{C}, 30 \mathrm{~s}$ at the annealing primer temperature and $1 \mathrm{~min}$ at $72^{\circ} \mathrm{C}$; the reaction ended with a final extension of $4 \mathrm{~min}$ at $72^{\circ} \mathrm{C}$. Amplicons were sequenced in both directions by the Colorado State University Proteomics and Metabolomics Facility (Fort Collins, CO) after a purification step using a Wizard SV Gel and PCR Clean-Up System (Promega, Madison, Wisconsin). Sequences were aligned using Muscle v 3.7 (Edgar 2004) with default 
parameters. Maximum-likelihood trees were generated from the aligned sequences using the following functions from the phangorn R package (Pruesse et al. 2012; Schliep 2011): modelTest, dist.ml (model = "JC69"), NJ, pml, optim.pml (model = "JC", rearrangement $=$ "stochastic"), and bootstrap.pml (bs = 100).

Bacterial multiplication in sucrose-rich media. Ability of aphid-associated bacteria to multiply in sucrose-rich media was measured in two ways. First, we cultured several aphid-associated bacteria (Acinetobacter sp. B114, Arthrobacter sp. B117, E. iniecta B120, Pantoea sp. B151, and Enterobacter sp. B156) in media with or without a high sucrose content. The $\mathrm{pH}$ for all media was adjusted to 7.0. Media included the following: Luria-Bertani broth (LB), LB with $15 \%$ sucrose, sterile distilled water, sterile distilled water with $15 \%$ sucrose. For the experiment, three cultures of each bacteria were grown in an overnight liquid culture of nutrient broth for $16 \mathrm{~h}$, washed two times, resuspended in distilled water, and adjusted to an $\mathrm{OD}_{600}$ of 0.2 . After 10-fold serial dilutions, 200- $\mu \mathrm{l}$ aliquots of three technical replicates of each of the bacterial cultures were pipetted into a 96 well microplate. The plates were incubated at $28^{\circ} \mathrm{C}$ with agitation in a plate reader (PowerWave HT, BioTek, U.S.), and the $\mathrm{OD}_{600}$ was measured hourly for $72 \mathrm{~h}$. In a second approach, we determined multiplication of bacteria in sucrose-rich artificial diets fed on by aphids by measuring turbidity $\left(\mathrm{OD}_{600 \mathrm{~nm}}\right)$ of sterile $15 \%$ sucrose solution and $15 \%$ sucrose solution from artificial diets after 24 and $48 \mathrm{~h}$ of aphid feeding.

Contribution of $D$. noxia-associated bacteria to aphid virulence. The contribution of bacteria to $D$. noxia virulence was assessed after reducing titers of bacteria associated with aphids in two ways. In these studies, the more virulent biotype, D. noxia biotype 2 was used. First, we fed aphids an artificial diet supplemented with antibiotics. Preliminary experiments showed that an artificial diet supplemented with rifampicin at $50 \mu \mathrm{g} / \mathrm{ml}$ and chlortetracycline at $50 \mu \mathrm{g} / \mathrm{ml}$ for $48 \mathrm{~h}$ maximized aphid survival while minimizing bacterial populations. The virulence of the antibiotic treated aphids was compared with aphids fed an artificial diet without antibiotics for $48 \mathrm{~h}$. Four 7-day-old TAM 107 wheat plants were infested with 50 antibiotic-treated or 50 untreated aphids per plant. This experiment was repeated four times for a total of 16 plants per treatment. Seven to ten days after infestation, the total number of aphids were counted (to measure any changes due to births or deaths) and the proportion of total leaf area that was chlorotic was measured using Image J 1.47v (Schneider et al. 2012). To assess any possible effects of antibiotics on the reproductive ability or survivorship of the aphids, we used a $t$ test to compare the number of antibiotic-treated and untreated aphids after 2 weeks on wheat plants. We used an ANCOVA to assess the effects of the antibiotic treatment on the logit-transformed proportion of chlorotic leaf tissue that developed after adjusting for the number of aphids per leaf (the covariate) (Lindman 2012).

To avoid potential effects of antibiotics on the obligate aphid symbiont B. aphidicola (Koga et al. 2003, 2007), we used a second method to reduce titers of facultative bacteria. Prior to each experiment, we established colonies of aphids on uninfested wheat plants from individual nymphs that had been isolated from their mother at birth before they initiated feeding. This technique allowed us to establish colonies of isolated aphids free of facultative bacteria that are transmitted from mother to offspring during cofeeding. Control aphid colonies (co-fed aphids) were established by allowing the new-born aphid to cofeed with its mother and siblings as the colony established. Twenty-four 14-day-old TAM 107 plants were infested with 15 adult aphids from either colony (12 plants with isolated aphids, 12 plants with co-fed aphids). After 10 days, aphid numbers were recorded and the proportion of total leaf area that was chlorotic was measured using Image J 1.47v (Schneider et al. 2012). Bacterial colony counts from randomly sampled aphids were conducted at the end of the experiment to ensure these aphids were still free of horizontally transmitted bacteria. Ten adult aphids from each plant were pooled and crushed into $50 \mu \mathrm{l}$ of Carlson's Solution and then the liquid was transferred onto nutrient agar amended with cycloheximide at $50 \mathrm{mg} / \mathrm{liter}$ (to eliminate fungal growth) to measure bacterial numbers. The number of bacteria isolated from isolated aphids and co-fed aphids were log $(\mathrm{N}+1)$ transformed and compared with a $t$ test. We used an ANCOVA to examine the effect of isolated versus co-fed aphids on the proportion of chlorotic leaf tissue induced (logit-transformed) after adjusting for the effects of the number of aphids present (the covariate).

Sample collection, DNA extraction, and sequencing of $16 \mathrm{~S}$ rRNA amplicons. Ten samples containing either 10 isolated or 10 co-fed adult aphids (biotype 2, five samples per treatment) were subjected to $16 \mathrm{~S}$ rRNA amplicon sequencing. An additional sample was sequenced that contained a mock community of 12 known bacterial isolates in equal concentrations (Supplementary Table S1) to assess contamination and sequencing errors. All aphids were reared on cultivar Yuma wheat plants for approximately 12 generations before collection for DNA extraction. Under sterile conditions, aphid DNA was extracted using the MoBio PowerSoil extraction kit as directed by the manufacturer, with the following deviations: (i) in the PowerBead Tubes, aphid samples were vortexed in a FastPrep bead beater at a speed of 5.0 for $2 \mathrm{~min}$, (ii) after the initial vortex step, $20 \mu \mathrm{l}$ of proteinase $\mathrm{K}(20 \mathrm{mg} / \mathrm{ml})$ was added to each sample and vortexed briefly, and (iii) samples were then incubated at $60^{\circ} \mathrm{C}$ for $1 \mathrm{~h}$. The protocol was followed until the elution step, where $30 \mu \mathrm{l}$ of solution C6 was added (first elution), and a second elution was performed with $20 \mu$ l of solution C6. In addition to the aphid samples, two tubes with no aphids served as negative controls to ensure reagents and technique did not contribute to contamination. For quality control, PCR using the V4 region of the $16 \mathrm{~S}$ rRNA subunit with the $515 \mathrm{~F} / 806 \mathrm{R}$ primer set was conducted at Colorado State University; all DNA from aphid samples amplified, but samples with no aphids did not amplify (Supplementary Fig. S1), suggesting contamination had not occurred, and were therefore not further processed.

Bacterial strains used for the mock community (positive control) were grown overnight at 28 or $37^{\circ} \mathrm{C}$ on nutrient agar (Becton, Dickinson and Company, Franklin Lakes, NJ). Genomic DNA was prepared using the EasyDNA kit (Life Technologies, Grand Island, NY) according to manufacturer's recommendations, except the final product was recovered in $50 \mu l$ of sterile molecular grade water. After DNA extraction and quantification, equal amounts of DNA from each strain were added together to create the mock community.

The first elutions of the aphid samples and the mock community were used for PCR amplification, pooling, library preparation and paired-end sequencing (MiSeq; $2 \times 150$ bp paired end reads) using $\mathrm{V} 4$ region of the $16 \mathrm{~S}$ rRNA gene with the $515 \mathrm{~F} / 806 \mathrm{R}$ primers at SeqMatic (Freemont, CA).

16S rRNA data processing and analyses. Sequencing reads were demultiplexed, and forward reads were processed using the open source bioinformatics platform Qiime 2 version 2017.10 (Caporaso et al. 2010). Briefly, sequence variances were detected using the DADA2 pipeline (Callahan et al. 2016) where chimeric sequences and phiX reads were removed. Taxonomy was assigned using a pretrained Naïve Bayes classifier (Bokulich et al. 2018) that was trained on the Greengenes database, but was also hand curated by alignment of sequences of unknown taxonomy from the feature table to genomes of D. noxia-associated bacteria. It is important to 
note that the Greengenes database does not include the newly described family Erwiniaceae (Adeolu et al. 2016). Therefore, when appropriate, family names have been edited to account for this change in taxonomy. Only sequences that matched nucleotides of sequenced genomes $100 \%$ were added to the feature table (Supplementary Fig. S2). Phylogenetic trees were generated by aligning sequences using the mafft program (Katoh and Standley 2013), and then alignments were filtered to remove variable positions. Once alignments were filtered, FastTree (Price et al. 2010) was used to create a phylogenetic tree with midpoint rooting. As the focus of this study was to look at facultative bacteria, sequences that mapped to Buchnera were removed and the remaining reads were rarified to a sampling depth of 425 reads. Alpha diversity was measured by observed operational taxonomic units (OTUs) and Faith's phylogenetic diversity (Faith 1992). Beta-diversity was evaluated using unweighted unifrac distances which were used to construct a principal component analysis to further investigate treatment differences. A PERMANOVA statistical test was used to determine if the two treatment groups differed at the beta diversity level. We tested the relative abundance of each taxon in the two aphid groups using the analysis of composition of microbiomes (ANCOM) compared the relative abundance of sequence variants between the two aphid treatments.

Inoculation of wheat leaves with bacteria. Approximately $5 \mu \mathrm{l}$ of bacterial resuspensions $\left(1 \times 10^{8} \mathrm{CFU} \mathrm{ml}{ }^{-1}\right)$ was infiltrated into 3week-old Byrd wheat leaves using a needle-less syringe (Reimers and Leach 1991). One to two representative aphid-associated bacterial isolates from each genus were used for inoculations, including: Acinetobacter spp. 114; Erwinia sp. 116 and 120; Arthrobacter sp. 117; Pantoea sp. 151; and Enterobacter sp. 156. Bacteria were infiltrated into the adaxial surface of plants individually or in combination (equal numbers of each bacterial strain). Controls for the experiment included a water control and Xanthomonas translucens (strain UPB787), a known pathogen of wheat (Langlois et al. 2017). Plants were observed at 24,48 , and $72 \mathrm{~h}$ for signs of chlorosis, browning, or water soaking.

Microarray data analysis. Expression of genes involved in the jasmonic acid (JA) and salicylic acid (SA) biosynthetic pathways in wheat were determined by reanalysis of data from a previously published microarray analysis (Botha et al. 2010). The original experimental design included RNA extracted from a susceptible wheat cultivar (Gamtoos) infested with Russian wheat aphid biotype 1 for 0,5 , and $48 \mathrm{~h}$, and included three replicates per treatment. Probe set IDs, annotated with respect to the JA or SA biosynthetic pathways, were extracted from the full data set and $\log _{2}$-fold changes in expression relative to the uninfested $0 \mathrm{~h}$ time point and were calculated for each probe set ID at $5 \mathrm{~h}$ postinfestation (hpi) and 48 hpi. Probe sets with an absolute value of $\log _{2}$-fold change $>1$ were considered to be differentially expressed, and probe sets with differential expression at either 5 or 48 hpi were included in our analysis.

Phytohormone quantification. JA and SA accumulation was assessed after aphid feeding on wheat leaves. Fourteen-day-old wheat plants (Yuma) were heavily infested with approximately $0.5 \mathrm{~g}$ of aphids $(\approx 2,500$ aphids) which were either isolated aphids or co-fed aphids, or plants were left uninfested. After 6, 24, or $48 \mathrm{~h}$, aphids were gently brushed off leaves using a fine bristled paint brush and the leaves were quickly weighed and placed in liquid nitrogen and stored at $-80^{\circ} \mathrm{C}$. Each time point consisted of three replicates and within each replicate, leaves of the same age from two or three plants were sampled and pooled to meet the required sample weight of $100 \mathrm{mg}$ of fresh tissue. Frozen leaves were ground using a tissue lyser (TissueLyser, Retsch, Qiagen), extracted with methanol (Almeida Trapp et al. 2014), dried under a stream of nitrogen, and shipped to The Samuel Roberts Noble Foundation (Ardmore, OK). Samples were resuspended in $100 \%$ methanol containing internal standards for JA and SA prior to separation, detection, and quantification (Pan et al. 2010; Watson et al. 2015). Relative amounts of SA and JA were based on comparisons to the labeled hormones. A two-way ANOVA was performed to evaluate the effects of time point $(6,24$, or $48 \mathrm{hpi})$ and aphid treatment (isolated aphids, cofed aphids, or no aphids). Hormone measurements were log transformed to meet assumptions of normality and analyzed using JMP Pro version 12.0.1. Differences between treatment levels were determined using a Tukey's HSD.

\section{RESULTS}

D. noxia saliva contains mostly bacterial peptides. To identify proteins secreted by aphids during feeding, a whole proteomic analysis of artificial diets fed on by $D$. noxia biotypes 1 and 2 were collected and analyzed using Mud-PIT and iTRAQ analyses. No proteins were detected in control artificial diets (which were not fed upon by $D$. noxia) after separation in SDS-denaturing gels or by Bradford protein assays (data not shown).

A total of 1,734 proteins (combined from $D$. noxia biotypes 1 and 2) were identified when the data were searched against all proteins in the NCBI database. Only 13 insect proteins were identified, and these were only from the family Aphididae. These proteins included apolipophorin, glucose dehydrogenase, trehalase and alanyl aminopeptidase, and S-adenosyl-L-homocysteine hydrolase (Supplementary Table S2), and all were consistently found in both biotypes 1 and 2 at a similar abundance, with the exception of S-adenosyl-Lhomocysteine hydrolase, which was detected only in biotype 2 .

Strikingly, of the 1,734 identified, most proteins $(78 \%)$ matched with bacterial proteins, particularly with those found in the families Enterobacteriaceae and Erwiniaceae (57\%) (Fig. 1A). Proteins matching four genera, Erwinia, Pantoea, Enterobacter, and Acinetobacter, were especially dominant. This observation was true for all three replicates of both $D$. noxia biotypes 1 and 2 .

To expedite database searching and to eliminate redundancy found in the large NCBI database, we constructed an in-house database that, guided by the NCBI search results, contained a combination of predicted proteins from aphids and prokaryotes. The prokaryotic proteins were predicted from microbes known to be associated with aphids, including Erwinia spp., Pantoea spp., Enterobacter spp., Acinetobacter spp., and insect endosymbionts belonging to the orders Enterobacteriales (Photorhabdus spp., ' $\mathrm{Ca}$. Hamiltonella defensa', 'Ca. Regiella insecticola', Arsenophonus spp., B. aphidicola, 'Ca. Carsonella ruddii', and Serratia symbiotica) and Rickettsiales (Wolbachia spp. and Rickettsia spp.). Comparisons of the D. noxia salivary proteins to this database revealed a total of 1,162 proteins comprising 562 protein families with more than $95 \%$ probability of identification with a minimum of two matching peptides (Supplementary Dataset S1). Among them, proteins from four genera Erwinia, Pantoea, Enterobacter, and Acinetobacter were predominant, representing 52, 23, 9.5, and $10 \%$ of the total matches, respectively (Fig. 1B). Proteins predicted to be from the insect endosymbionts Photorhabdus spp. Arsenophonus spp., 'Ca. Regiella insecticola', 'Ca. Hamiltonella defensa', and Serratia symbiotica together totaled only $4.1 \%$. Consistent with comparisons to the entire NCBI nonredundant database (Fig. 1A), only $1 \%$ of the proteins detected were of aphid origin. No matches were observed with other possible aphid endosymbionts, such as 'Ca. Carsonella ruddi', B. aphidicola, or any members of the Rickettsieae.

The bacterial proteins identified in the artificial diet after feeding were predominantly associated with bacterial housekeeping 
functions (Supplementary Fig. S3). Most were associated with metabolism (37\%), ribosome and protein synthesis (16\%), DNA maintenance and gene expression $(13 \%)$, membrane transporters $(7.8 \%)$, membrane synthesis and maintenance $(8 \%)$, proteases and chaperones $(5.7 \%)$, and stress $(5.5 \%)$. Three bacterial virulence factors associated with virulence-related outer membrane proteins and the type VI secretion system were identified (type VI secretion ATPase, ClpV1 family; VI secretion system effector, Hcp1 family; type VI secretion system effector, Hcp family). In addition, we identified proteins associated with microbe-associated molecular patterns (MAMPs), such as flagellin.

As sucrose is an important carbon source for many bacteria, we conducted an experiment to determine if the high number of bacterial peptides in artificial diets (sterile $15 \%$ sucrose solution in water) that had been fed on by $D$. noxia were an artifact of an environment conducive to bacterial growth. Aphid-associated bacteria do not multiply in the sucrose-rich artificial diets (Supplementary Fig. S4) nor did turbidity $\left(\mathrm{OD}_{600 \mathrm{~nm}}\right)$ of artificial diets change after $48 \mathrm{~h}$ of aphid feeding (Supplementary Table S3).

Diuraphis noxia release bacteria during feeding. We previously demonstrated that bacteria can be cultured from artificial diets fed upon by D. noxia (Campillo et al. 2015). Based on our proteome study, $D$. noxia was expected to release Gram-negative bacteria, predominantly in the order Enterobacteriales. Given that D. noxia biotype 2 is the more virulent aphid and that there was little difference in overall bacterial composition in the proteome study between the two biotypes, biotype 2 was chosen for this study. To determine if the proteome predictions corresponded with culturable bacteria, taxonomic groupings were determined for isolates from three sources: (i) artificial diets, (ii) D. noxia, and (iii) wheat leaves. Bacteria were not recovered from artificial diets or surface-sterilized wheat leaves that had not been exposed to aphids.

Phylogenetic analysis based on the rrs (16s rRNA) sequences placed the isolates into four bacterial families: Paenibacillaceae, Moraxellaceae, Enterobacteriaceae, and Erwiniaceae. Twelve Paenibacillaceae strains, isolated from crushed aphids or wheat leaves after aphid feeding, exhibited more than 99\% DNA sequence identity, and all clustered into the genus Paenibacillus (data not shown). Since the Paenibacillus were not isolated from artificial diets after $D$. noxia feeding, they were not included in further phylogenetic analyses.

Isolates representing each taxonomic group recovered from the crushed aphids and from artificial diets and wheat leaves probed by aphids (Supplementary Table S4) grouped into five different clusters at the genus level (Fig. 2, Supplementary Fig. S5). These five clusters show more than $99 \%$ identity with four genera: three within the Enterobacteriales (Erwinia, Pantoea, and Enterobacter), and one in the Pseudomonadales (Acinetobacter). One group of Erwinia isolates that was frequently recovered from all three sources was recently named Erwinia iniecta (Campillo et al. 2015). These results are consistent with the results of our proteome analysis. Furthermore, the same groups of bacteria were recovered from bodies of both biotypes of D. noxia, as well as from artificial diets and surface sterilized wheat leaves that had been in contact with or infested with $D$. noxia. Thus, we propose that $D$. noxia

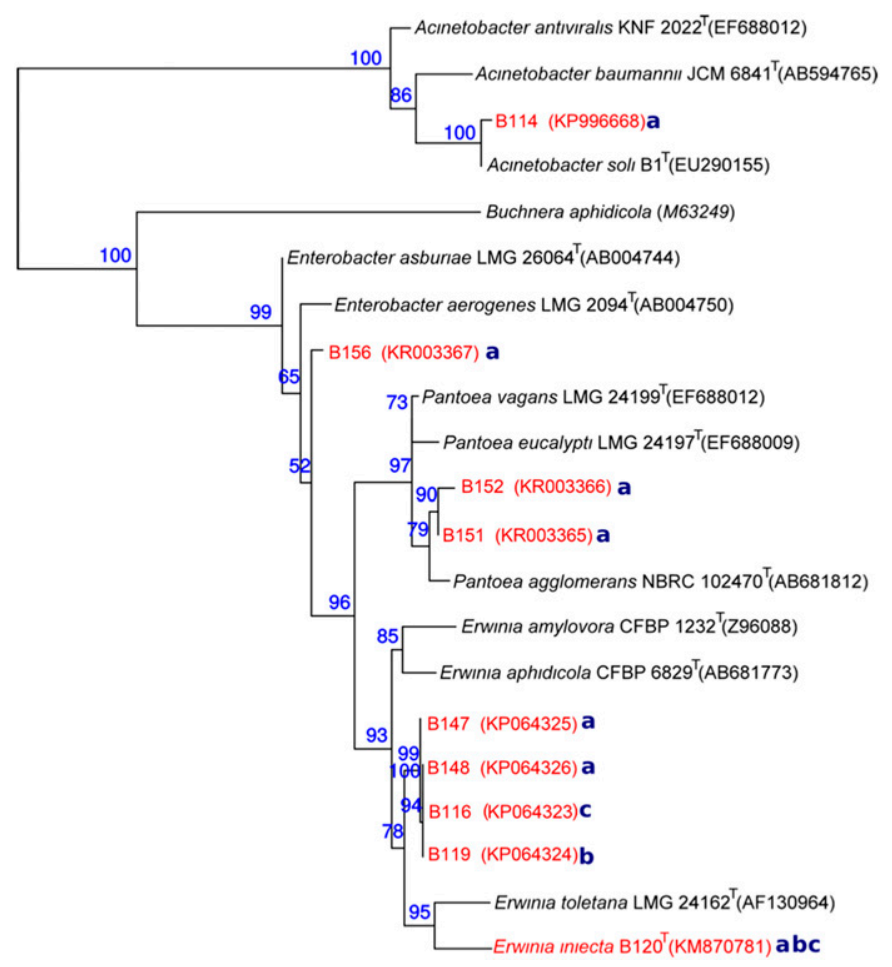

Fig. 2. Maximum-likelihood trees built from sequences corresponding to the PCR product FD1-RP2 of bacteria isolated from artificial media fed on by Diuraphis noxia (a), crushed $D$. noxia (b), or wheat leaves after exposure to $D$. noxia (c). Bacterial isolates from this study are shown in red. GenBank accession numbers are given in parentheses. Type strains are indicated by a superscript $\mathrm{T}$.
A

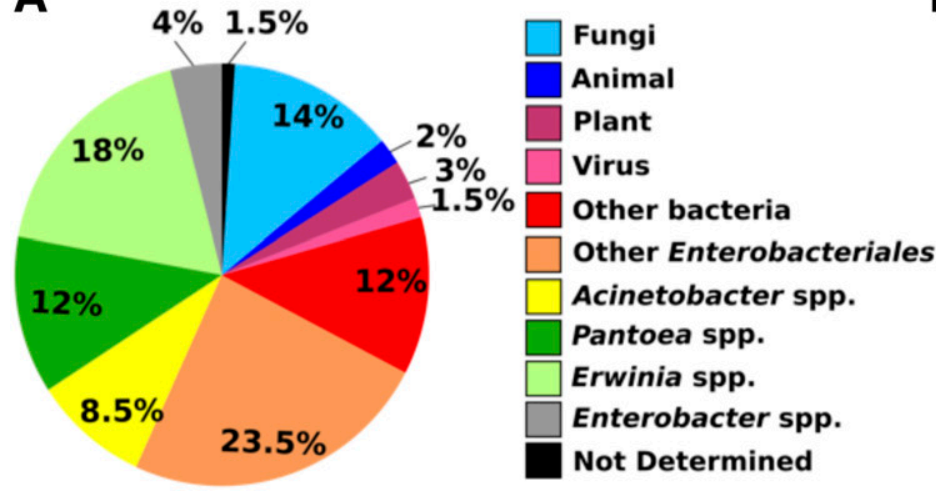

B

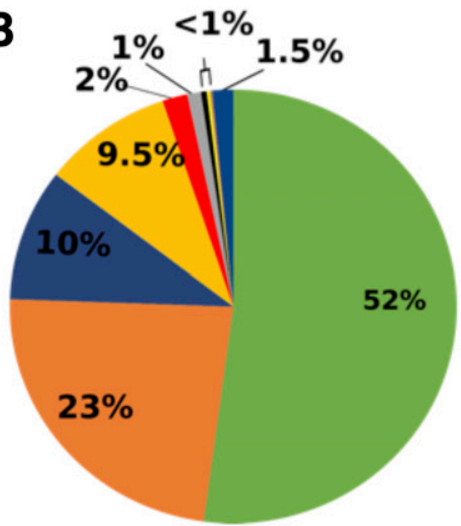

Erwinia spp.

Pantoea spp.

Acinetobacter spp.

Enterobacter spp. Photorhabdus spp.

Aphididae

Regiella insecticola

Arsenophonus spp.

Hamiltonella defensa

Serratia symbiotica

Fig. 1. The Diuraphis noxia salivary proteome is mostly composed of bacterial proteins, with very few insect proteins detected. A, Analysis of 1,734 proteins from $D$. noxia saliva by MASCOT comparison against the entire NCBI nonredundant database. B, Analysis of $1,162 D$. noxia salivary proteins against a custom-built database that includes protein sequences from the family Aphididae, and from prokaryotes known to be associated with aphids. 
delivers bacteria, and predominantly Enterobacteriales, into plants via the stylet during feeding.

Aphid-associated bacteria enhance $D$. noxia virulence. To facilitate studies to determine the role of aphid-associated bacteria in virulence to plants, we established colonies of aphids with reduced bacterial numbers in two ways. First, we generated aphid populations with reduced bacterial numbers by treating them with antibiotics (rifampicin and chlortetracycline) for $48 \mathrm{~h}$. Antibiotic treatment led to a reduction of bacterial numbers by 10 - to 100 -fold in comparison with untreated controls. Plants fed upon by aphids not treated with antibiotics exhibited more chlorotic symptoms than plants fed upon by aphids after antibiotic treatment (partial- $F_{1,28}=$ $10.94, P=0.0026$ ), indicating a role for the bacterial communities in RWA virulence. Antibiotic treatment did not negatively affect aphid survival or reproduction, as seen by the similar numbers of aphids recovered from susceptible wheat plants 7 to 10 days after feeding with antibiotic-treated or untreated aphids $\left(\mathrm{t}_{21}=0.88, P=\right.$ 0.39; Supplementary Fig. S6).

As a second means to determine the contribution of bacteria to aphid virulence and to rule out any possible negative effects of antibiotic use on the aphid feeding, we assessed the virulence of isolated aphids relative to co-fed aphids to susceptible wheat plants. Isolation of nymphs from their mothers at birth (isolated) resulted in nearly 100-fold less bacteria than the counts from co-fed aphids, where the nymphs were allowed to feed adjacent to their mothers, siblings and progeny $\left(\mathrm{t}_{21}=8.62, P<0.001\right.$; Fig. 3A). After 14 days of feeding, we recovered similar numbers of aphids from susceptible plants exposed to isolated or co-fed aphids ( $\mathrm{t}_{35}=1.08, P=$ 0.29 ; Fig. 3C) showing that the isolated aphids were not obviously reduced in fitness during the course of this experiment. Aphids from colonies where individuals were allowed to feed alongside their mothers induced more chlorosis on susceptible wheat plants than did aphids from colonies where individuals were isolated at birth (partial $=F_{1,33}=20.33, P<0.001$; Fig. 3B).

To address if aphid-associated bacteria were the cause of chlorosis, rather than the aphids themselves, wheat leaves were infiltrated with suspensions of the six bacterial groups most frequently isolated from aphids. None of the bacteria tested individually or in combination induced chlorosis or any other phenotype on wheat leaves, showing that the bacteria were not the cause of the chlorotic phenotypes after aphid feeding (Fig. 4). Taken together, these support that the presence of bacteria enhances aphid-induced chlorosis on susceptible wheat plants, but that the bacteria themselves are not the cause of chlorosis.

Isolated aphids harbor fewer Enterobacteriales and Pseudomonadales than co-fed aphids. To identify differences in the taxonomic groups of bacterial associates that might contribute to enhanced virulence of co-fed $D$. noxia, we used amplicon sequencing data to compare microbiomes of isolated and co-fed $D$. noxia. Controls included DNA extractions from samples without aphids (negative control) and a mock community (positive control). Samples without aphids did not amplify with the V4 primers, indicating the samples were free of template DNA, and, thus, were not included in downstream analysis. The sequencing of the mock community accurately predicted the 12 bacteria added to the mock

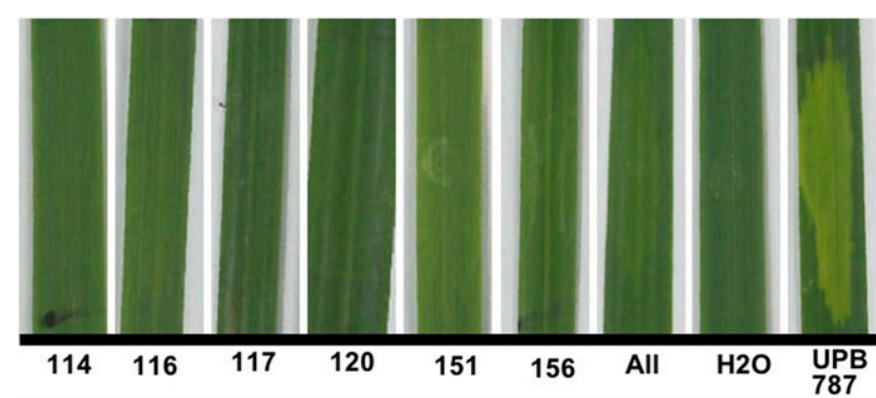

Fig. 4. Bacterial strains isolated from Diuraphis noxia do not induce chlorosis, water soaking, or necrotic symptoms on wheat. Bacterial strains used for inoculations were Acinetobacterspp. 114; Erwinia sp. 116 and 120; Arthrobacter sp. 117; Pantoea sp. 151; and Enterobacter sp. 156. Bacteria were infiltrated into the adaxial surface of plants individually or in combination (All, including equal numbers of each bacterial strain). Controls were water $\left(\mathrm{H}_{2} \mathrm{O}\right)$ and Xanthomonas translucens (strain UPB787), a known pathogen of wheat. Only $X$. translucens showed symptoms (water soaking).
A

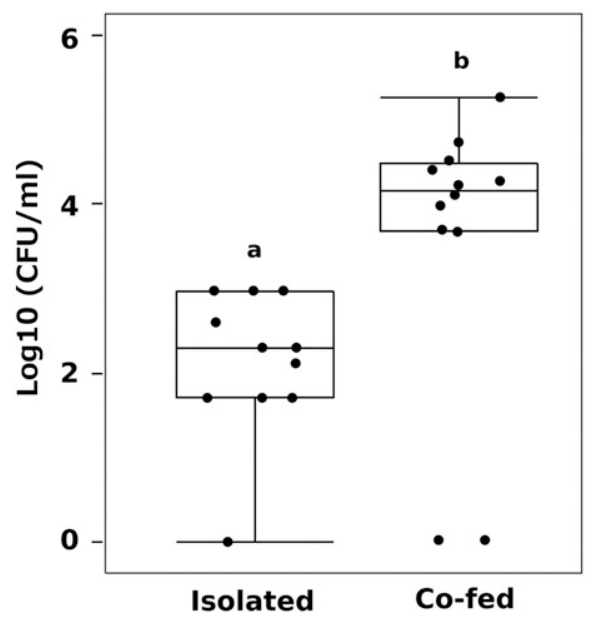

B

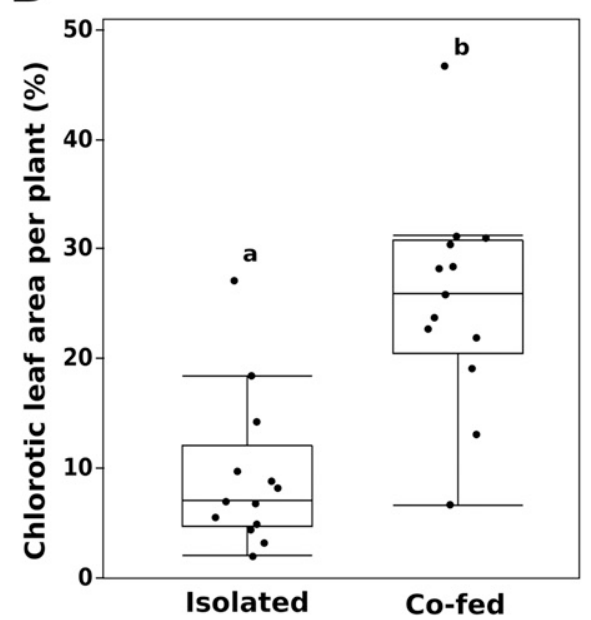

C

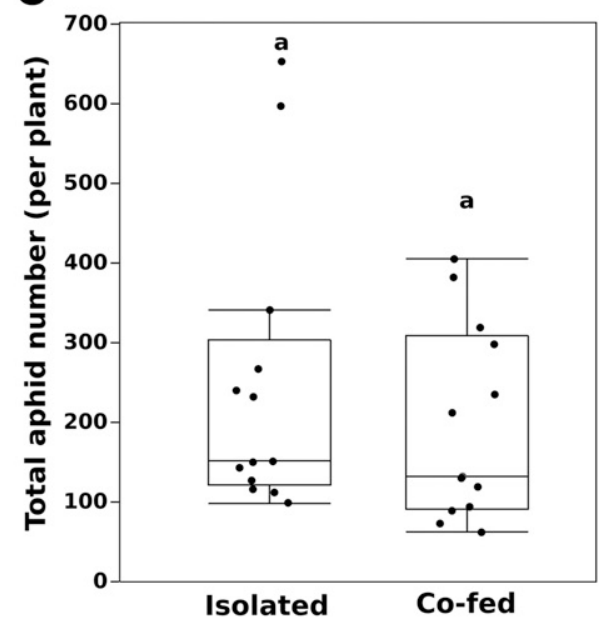

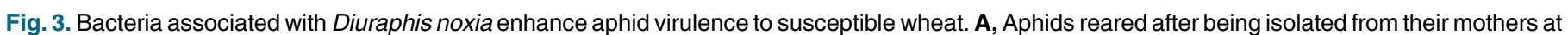

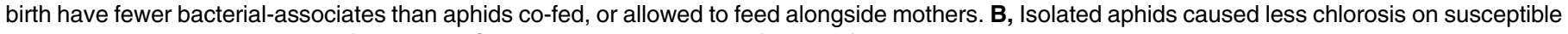

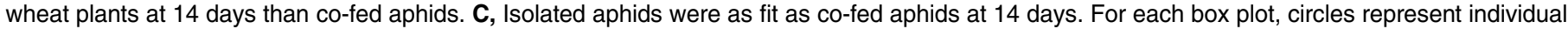

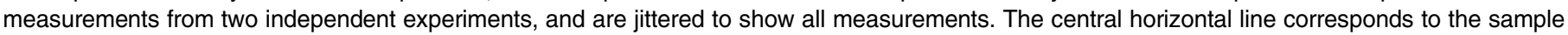

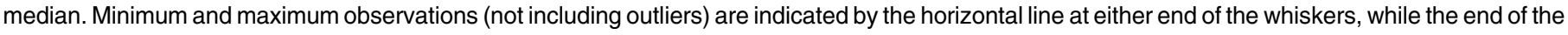
box represents the interquartile range (between 25 and 75\%). 
community and were thus not included in downstream comparative analyses. Note that the mock community included seven representatives of different genera from $D$. noxia isolated in this study.

Isolated aphid samples harbored bacterial communities with fewer OTUs and lower Faith's phylogenetic diversity than co-fed aphid samples suggesting less diversity, but the differences were not significant $(P=0.86$ and 0.18 , respectively; Supplementary Fig. S7A and B). Bray Curtis's dissimilarity matrix analysis showed that bacterial communities from isolated and co-fed aphid samples group separately, indicating differences in bacterial communities.

Members of the families Enterobacteriaceae, Erwiniaceae, and Moraxellacae dominated the co-fed aphid microbiome (Figs. 5A and 6A). Across co-fed samples, up to $80 \%$ of the reads remaining after subtraction of Buchnera reads belong to taxa associated with these three families (Figs. 5A and 6A). This is in contrast to the isolated microbiome, where taxa associated with Enterobacteriaceae, Erwiniaceae, and Moraxellacae were attributed to less than $20 \%$ of the non-Buchnera reads (Figs. 5B and 6A). Interestingly, one significant sequence variant identified to the family level as Enterobacteriaceae (including Erwiniaceae) by ANCOM analysis (Fig. 6B) was dominant in co-fed communities but absent from isolated aphid microbial communities (Fig. 6A). The sequence was a perfect match to the 16s rRNA region of Erwinia iniecta (Fig. 6C), but could also match other related Erwiniaceae. Together, these data show that co-fed aphids are enriched in families of bacterial associates (Enterobacteriaceae, Erwiniaceae, and Moraxellacae) that were predicted in the salivary proteome and that were cultured from aphids and aphid-infested wheat (Figs. 1 and 2). Furthermore, at least one bacterial associate is absent in isolated aphid microbiomes (Fig. 6C), and based on the sequence, these missing bacteria could be E. iniecta, bacteria frequently cultured from and known to be associated with natural populations of D. noxia (Campillo et al. 2015; E. Luna and J. E. Leach, unpublished data).

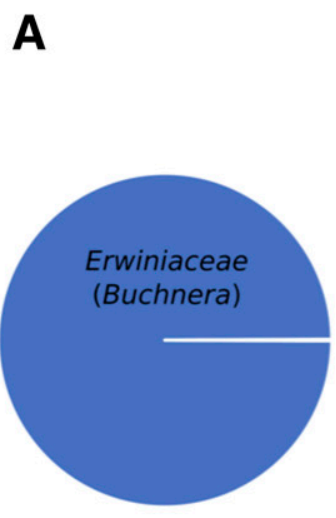

\section{Co-fed}
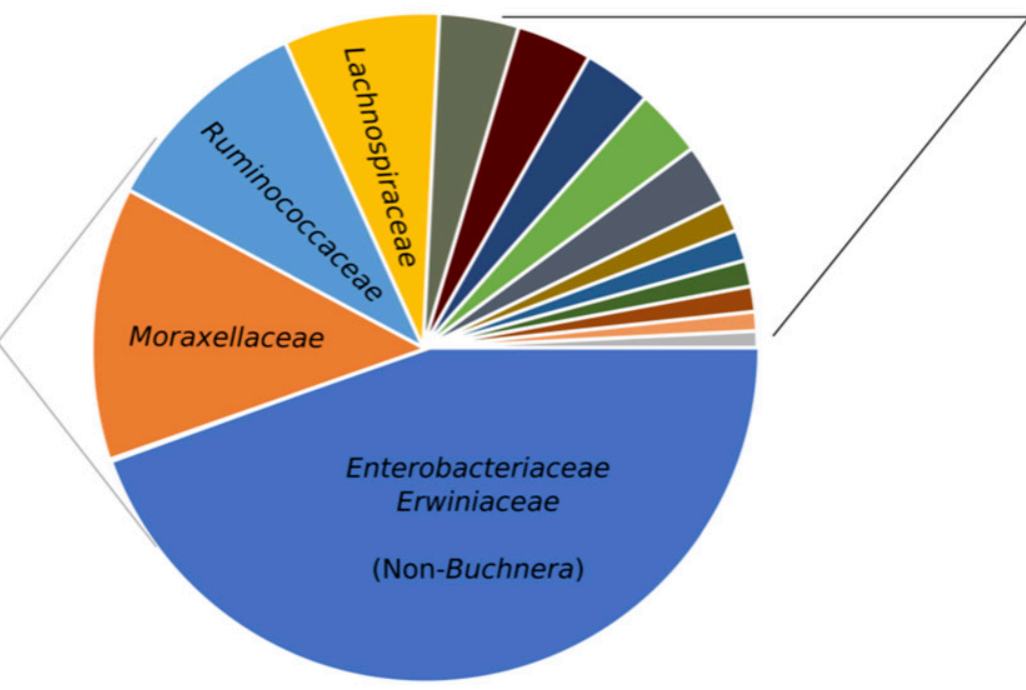

- Pseudonocardiaceae

- Staphylococcaceae

- Micrococcaceae

- Methylobacteriaceae

- Veilonellaceae

- Weeksellaceae

- Acetobacteraceae

- Caulobacteraceae

- Chitinophagaceae

- Sphingomonadaceae

- Bifidobacteriaceae

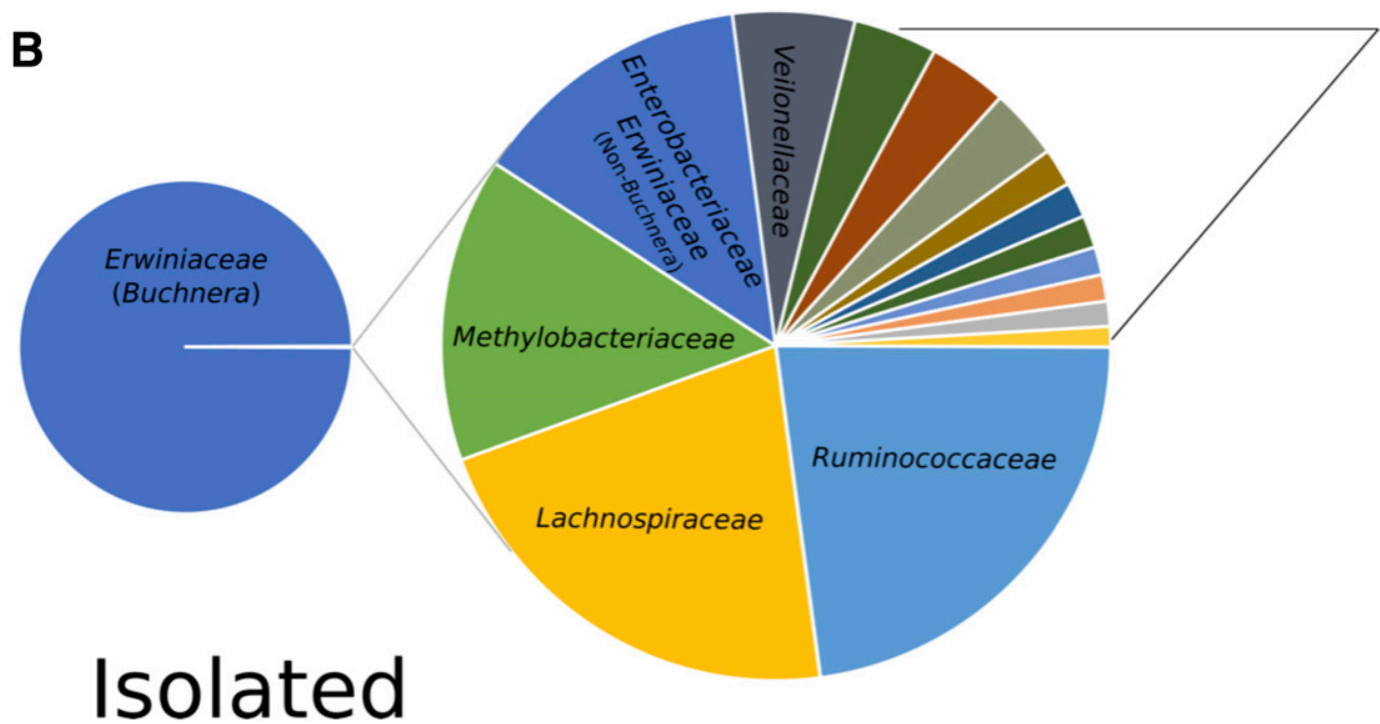

- Caulobacteraceae

- Chitinophagaceae

- Bacteroidaceae

- Porphyromonadaceae

- Prevotellaceae

- Moraxellaceae

- Sphingomadaceae

- Rhizobiaceae

- Weeksellaceae

- Brevibacteriaceae

Fig. 5. Classification of family-level bacterial taxa associated with Diuraphis noxia, as predicted by $16 \mathrm{~s}$ rRNA amplicon sequencing. DNA pools from aphids that $\mathbf{A}$, were allowed to feed alongside their mothers, siblings, and daughters (co-fed), or $\mathbf{B}$, were isolated from their mothers at birth (isolated). Over $99 \%$ of the 2,052,185 reads obtained mapped to the aphid endosymbiont Buchnera aphidicola. Remaining reads from replicated samples for each treatment were averaged and the most abundant 15 sequence variants were presented in the figure. 
D. noxia feeding induces both the JA and SA signaling pathways. We reanalyzed data from (Botha et al. 2010) for the effect of aphid colonization (co-fed aphids) on wheat genes encoding enzymes from the biosynthetic pathways of the plant hormones SA and JA, which are known to regulate responses to biotrophic pathogens/sucking insects and chewing insects, respectively. In general, most JA (16/18) and SA (6/6) biosynthetic genes were up-regulated by co-fed aphid infestation at $5 \mathrm{~h}$, in comparison with mock-infested wheat plants (Fig. 7A, Supplementary Table S5). However, by $48 \mathrm{hpi}$, most (13/18) JA probe sets were down-regulated relative to mock, while most (4/6) SA probe sets remain up-regulated. Thus, infection by Russian wheat aphid in wheat leads to an initial induction, followed by a down-regulation of genes involved in JA production, and sustained induction of genes involved in SA production during $D$. noxia feeding.

Accumulation of SA and JA were assessed after infestation of susceptible wheat leaves with co-fed and isolated $D$. noxia to determine if hormone levels were associated with presence of aphid bacterial associates. SA accumulation was induced earlier and to higher levels in plants infested with aphids that harbor higher microbe numbers (co-fed) relative to aphids with reduced bacterial numbers (isolated) $\left(\mathrm{F}_{8,18}=54.37, P<0.0001\right.$; Fig. $\left.7 \mathrm{C}\right)$. SA did not accumulate over time in plants not attacked by aphids (time*treatment interaction partial- $\mathrm{F}_{4,18}=15.69, P<0.0001$ ). At $24 \mathrm{hpi}$, $\mathrm{SA}$ accumulation in plants treated with co-fed aphids was over four times higher than plants attacked by isolated aphids. At $48 \mathrm{hpi}$, SA levels in leaves did not differ between infestations with both co-fed and isolated aphids but was still induced relative to SA levels in uninfested plants (Fig. 7C). JA was barely detectable in all samples, and was not significantly different in any treatment relative to controls (Fig. 7B). However, trends in JA accumulation are consistent with earlier and higher induction by co-fed aphids relative to isolated aphids, with a reduction to background levels by $48 \mathrm{hpi}$ (ANOVA: $F_{8,18}=0.8670, P=0.5606$ ). While the trends from JA gene expression and accumulation are not conclusive, our data show that co-fed aphids induce earlier and higher expression and accumulation of SA in wheat leaves than aphids with fewer bacterial associates.

\section{DISCUSSION}

In this study, we show that bacteria associated with $D$. noxia facilitate aphid virulence. $D$. noxia release both bacterial proteins and bacteria, mostly Enterobacteriales, during feeding on artificial diets, as demonstrated by proteome analysis and bacterial cultivation and identification. These aphid-associated bacteria, which were also isolated from aphid-infested wheat and are dominant members of the aphid microbiome, play a role in $D$. noxia virulence, because when bacterial numbers on aphids were experimentally reduced, the aphids caused less chlorosis on wheat.

Previous aphid saliva proteome studies did not report detection of bacterial proteins (Atamian et al. 2013; Bos et al. 2010; Carolan et al. 2011; Cooper et al. 2010; Harmel et al. 2008; Nicholson et al. 2012; Rao et al. 2013; Vandermoten et al. 2014), or, if they did, they revealed only a few matches with obligate endosymbionts such as B. aphidicola (Chaudhary et al. 2014; Elzinga et al. 2014). This discrepancy with our findings can be explained by the distinct databases used for the protein comparisons. Studies that did not
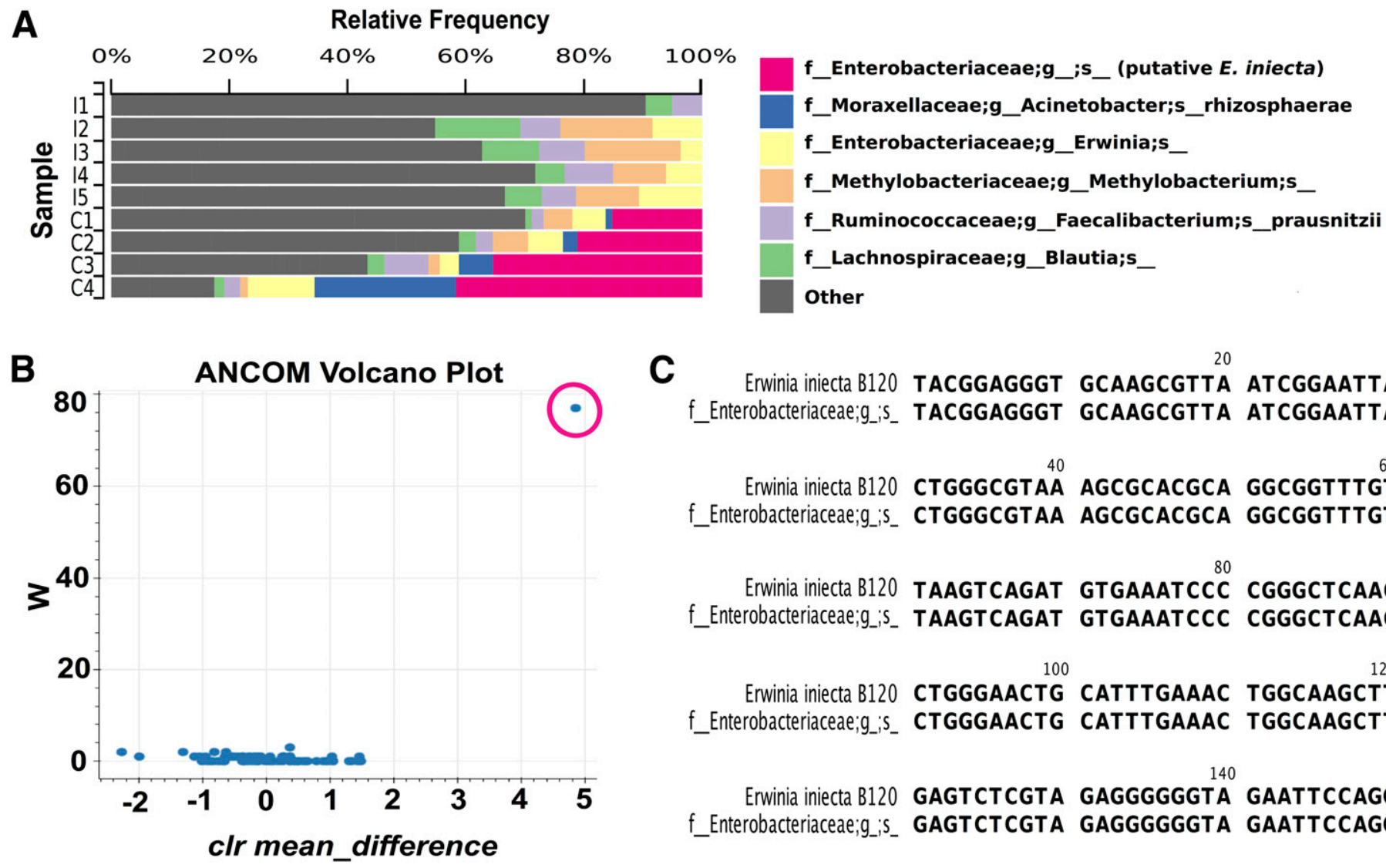

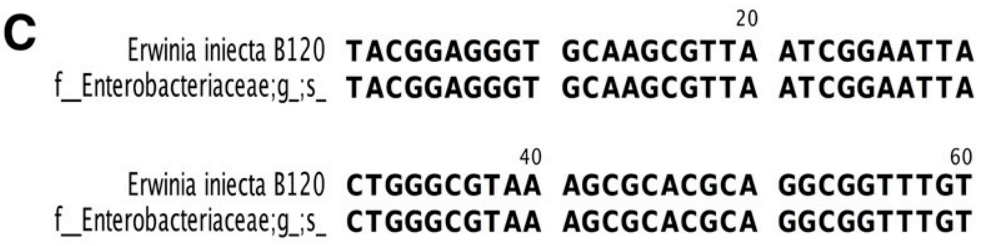

Fig. 6. A, Percent abundance of species level taxonomy from isolated aphids (samples I1 to I5) and co-fed aphids (samples C1 to C4). In legend, $f_{-}$ represents family and s_represents species. B, Analysis of composition of microbes (ANCOM) volcano plot showing significant sequence variant (circled in pink). C, Nucleotide alignment of significant sequence variant (circled in pink in B) to the $16 \mathrm{~S}$ rRNA sequence from Erwinia iniecta. 
A

membrane lipids

$\omega-3$ fatty acid desaturase

linolenic acid

lipoxygenase

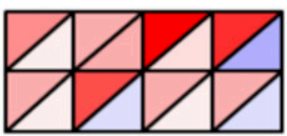

13(S)-hydroperoxylinolenic acid

allene oxide

synthase

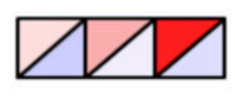

13,13(S)-epoxylinolenic acid

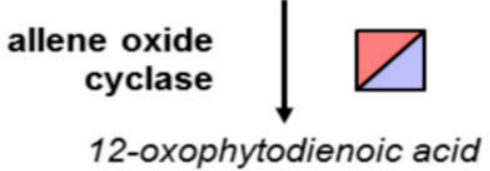

12-oxo-PDA
reductase

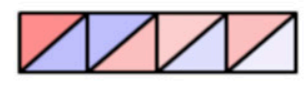

3-oxo-2-(cis-2'-pentenyl)-

cyclopentane-1-octanoic acid

I

!

jasmonic acid chorismic acid

chorismate

mutase

prephenic acid

prephenate

dehydratase

L-phenylalanine

\section{phenylalanine ammonia lyase}

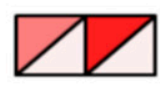

trans-cinnamic acid

4-coumarate:

CoA ligase

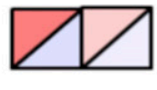

cinnamoyl-CoA

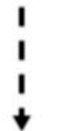

salicylic acid

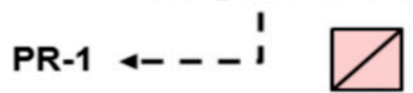

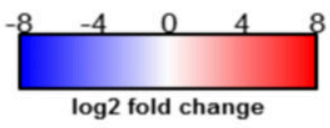

B

C

JA, aphid infested wheat leaves

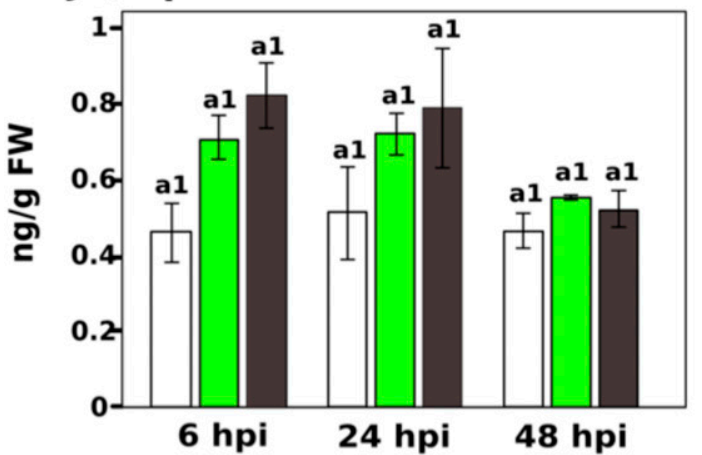

SA, aphid infested wheat leaves

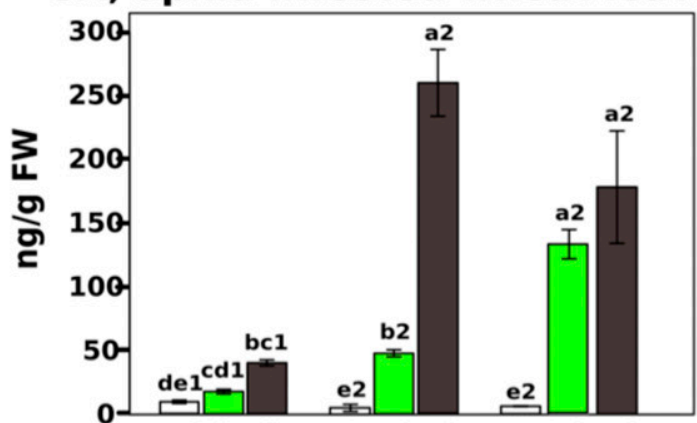

6 hpi

24 hpi 48 hpi

\section{$\square=$ uninfested plants}

Fig. 7. A, Genes encoding jasmonic acid (JA) and salicylic acid (SA) pathway enzymes in wheat are induced by Diuraphis noxia biotype 1 feeding. Expression was assessed at 5 and $48 \mathrm{~h}$ postinfestation (hpi) of wheat leaves (Botha et al. 2010). Each square represents the log ${ }_{2}$-fold change in expression of a probe set ID with homology to a biosynthetic enzyme gene. The top-left half of each square represents expression at 5 hpi, and the bottom-right half represents expression at $48 \mathrm{hpi}$. Accumulation of B, JA and C, SA in susceptible, 14-day-old wheat leaves (cultivar Yuma) 6 and $48 \mathrm{~h}$ after infestation treatments of isolated or co-fed aphids or no aphids (uninfested plants). Bars with different letters indicate differences across time and treatment and numbers show differences across time points only. A two-way analysis of variance evaluated the effects of time point (6, 24 , or $48 \mathrm{hpi}$ ) and aphid treatment (isolated aphids, co-fed aphids, or no aphids). Hormone measurements were log transformed to meet assumptions of normality. Differences between treatment levels were determined using Tukey's honest significant difference test. 
report any bacterial proteins used a restricted insect/arthropod database (excluding all other eukaryote/prokaryote proteins) and studies that reported a few endosymbiont proteins used separate insect/arthropod and endosymbiont databases (excluding all other prokaryote/eukaryote proteins). In our study, MS/MS spectra were searched first against the whole nonredundant NCBI database (Fig. 1A). This exhaustive comparison showed that most of the identified proteins were of bacterial origin, and many of those were enterobacterial proteins. Some of these proteins identified as 'other Enterobacteria' were predicted to be from various species such as Escherichia coli, Yersinia pestis, or Salmonella enterica. Because most identified bacterial proteins are highly conserved across genera (ribosomal proteins, membrane proteins, etc.), and because human pathogens are unlikely to be associated with aphids, their presence was assumed to be an artifact. The lack of specific sequence information for each bacterial species present in the diet necessitated homology-based searching to closely related species. As such, many proteins were identified on the basis of one or a few matching peptides. Therefore, we built a database that included protein sequences from the Aphididae and from species of the four predominant genera identified from aphids, i.e., Erwinia, Pantoea, Enterobacter, and Acinetobacter, as well as aphid endosymbionts. Comparisons with this database grouped proteins initially identified as human pathogenic Enterobacteria to one of the four predominant genera (Fig. 1B), and provided additional support that the D. noxia saliva proteome is mostly comprised of bacterial proteins, especially enterobacterial proteins, with very few proteins from the insect.

Several of the bacterial genera identified as associated with D. noxia are typically epiphytic or plant-pathogenic bacteria (Brady et al. 2010; Martinec and Kocur 1964), although some are known to associate with insects (Ellers-Kirk and Fleischer 2006; Estes et al. 2009; Garcia-Salazar et al. 2000; Gitaitis et al. 2003; Hildebrand et al. 2000; Skrodenytė-Arbačiauskienè et al. 2012; Stavrinides et al. 2010; Wells et al. 2002), and, in particular with aphids (Campillo et al. 2015; Capuzzo et al. 2005; Clark et al. 2012; Harada et al. 1997; Plurad et al. 1965). The presence of bacteria from the genus Erwinia is not uncommon in aphids. For example, Erwinia or Erwinia-like bacteria were detected in studies of aphids from the genus Cinerea as well as in the pea aphid, A. pisum (Gauthier et al. 2015; Jousselin et al. 2016). Some bacteria in the taxonomic groups we detected, including E. iniecta isolated from D. noxia, harbor genes responsible for delivery of bacterial virulence or effector proteins to plant and animal cells (Campillo et al. 2015). Thus, the delivery of these bacteria to plants via aphid feeding, and their requirement for full aphid virulence to wheat plants, begs the question of what the collective role of these microbes is in this multipartite interaction.

None of the bacteria isolated from the aphids or saliva caused damage to wheat leaves when infiltrated individually or in combination (Fig. 4). Further experiments with aphids harboring a known and/or controlled microbial flora would be required to identify which individual or combined microbial species facilitate aphids in causing plant damage. Although other facultative endosymbionts that exist in the aphid hemolymph (e.g., Hamiltonella, Regiella, Rickettsia, and Serratia) are vertically transmitted (Chen and Purcell 1997), it is reasonable to speculate that the culturable bacteria identified in the present study as associated with $D$. noxia are transmitted horizontally. Uninfected aphids may acquire bacteria as they cofeed on the same plants where infected aphids had defecated or injected their bacteria-laden salivary secretions. Indeed, such bacteria may be efficiently transferred from mother to offspring in this manner, because by removing nymphs from their mothers at birth, we were able to establish aphid colonies with reduced bacterial numbers (Fig. 3A) and with an altered microbiome composition (Figs. 5 and 6A). As mother aphids viviparously reproduce, their young aphid offspring may acquire their mother's suite of salivary-bacteria as they feed on the same plant tissue as their nearby mother.

Analysis of the proteome in artificial diets after D. noxia feeding has been the subject of studies focused on identifying virulence factors in aphid saliva. Similar to previous proteomic analyses of D. noxia saliva, we identified enzymes such as glucose dehydrogenase, trehalase or aminopeptidase $\mathrm{N}$-like and apolipophorin after feeding of both $D$. noxia biotypes 1 and 2 (Cooper et al. 2010; Nicholson et al. 2012). These released aphid proteins have been hypothesized to suppress plant defenses, but this has not been experimentally validated and their role in plant responses remains unclear (Elzinga and Jander 2013; Rodriguez and Bos 2013). Despite the fact that aphids transmit $\approx 30 \%$ of all plant viruses (Brault et al. 2010), D. noxia is considered a poor vector of viruses (Halbert et al. 1994; Summers et al. 1990). Furthermore, no typical aphid effectors have been reported in any proteome studies (Cooper et al. 2013; Nicholson et al. 2012), including ours, and no genes encoding aphid effectors were identified in the $D$. noxia genome (Burger and Botha 2017; Nicholson et al. 2015). It is interesting to consider whether, in this phytobiome, the lack of aphid salivary effectors, the inability to transmit plant viruses, and the requirement of the bacteria for the aphid to induce damage to plants are linked. In the absence of $D$. noxia effectors, one hypothesis is that bacterial effectors or other microbial elicitors such as MAMPs (microbialassociated molecular patterns) (Ausubel 2005; Jones and Dangl 2006) delivered by the aphid alter the plant's physiology to favor aphid feeding.

How the bacterial associates contribute to increased aphid virulence is not yet known. Altered regulation of the SA and JA responses have been reported for other plant interactions involving chewing insects (Chung et al. 2013) and stylet-feeding insects (Schwartzberg and Tumlinson 2014; Su et al. 2015), and bacteria are solely or partially responsible for modulation of the plant hormones in at least some of these interactions. Thus, we tested for variation in SA and JA gene expression and hormone accumulation in D. noxia-wheat. With extended aphid feeding (48 h), expression of JA biosynthetic genes that are related to insect defense responses decreased, whereas expression of SA biosynthetic genes that are related to biotrophic pathogen defense responses did not. Further, aphids with experimentally reduced bacterial titers induced less SA accumulation and less damage in wheat plants when compared with aphids with full bacterial titers. Regulation of gene expression and physiological outputs of SA and JA in wheat can be antagonistic (Ding et al. 2016). Although this antagonism is less clear for monocot interactions (Thaler et al. 2012), it is tempting to speculate that the aphid-associated bacteria facilitate aphid feeding by altering hormone regulation.

Insect-microbe associations that influence the impact of plant defenses are likely widespread. Findings from this work will broadly inform us about how such associations function to overcome plant defenses in both wheat as well as other aphidbacteria-plant systems. Our work highlights that bacteria are key for $D$. noxia to cause damage on susceptible wheat plants, and our preliminary data suggest that the bacteria may help $D$. noxia avoid basal plant defenses. We have not explored if variation in aphidassociated bacteria is related to resistance of wheat to D. noxia, or if bacterial content is related to $D$. noxia biotype. Our microbiome analysis and the isolation of aphid-associated microbes are first steps to better defining which bacteria within this phytobiome are important, and how and when the bacteria and aphids collaborate to counteract or induce different plant defense responses in the 
context of the wheat plant. Together, these studies may provide novel insights for control of this serious pest of one of the world's staple food crops.

\section{ACKNOWLEDGMENTS}

We thank F. Peairs, J. Rudolf, and D. Cockrell from the Colorado State University Insectary for rearing RWA, T. Fish and K. Howe from the USDA-ARS in Ithaca for technical assistance with protein sample preparation and peptide analysis, C. Ruse and K. Rivera from Cold Spring Harbor Laboratory for assistance with the LC-MS methods, J. Long and T. Aubol for technical assistance, J. Lang for providing DNA for the mock community, R. Davidson for advising on experimental design of 16s rRNA gene sequencing, and A. Hess for statistical consulting. N. Lapitan was not at USAID when the research for the current paper was conducted. The views and opinions expressed in this paper are those of the authors and not necessarily the views and opinions of the United States Agency for International Development.

\section{LITERATURE CITED}

Adeolu, M., Alnajar, S., Naushad, S., Gupta, R. S. 2016. Genome-based phylogeny and taxonomy of the 'Enterobacteriales': Proposal for Enterobacteriales ord. nov. divided into the families Enterobacteriaceae, Erwiniaceae fam. nov., Pectobacteriaceae fam. nov., Yersiniaceae fam. nov., Hafniaceae fam. nov., Morganellaceae fam. nov., and Budviciaceae fam. nov. Int. J. Syst. Evol. Microbiol. 66:5575-5599.

Almeida Trapp, M., De Souza, G. D., Rodrigues-Filho, E., Boland, W., and Mithofer, A. 2014. Validated method for phytohormone quantification in plants. Front. Plant Sci. 5:417.

Anathakrishnan, R., Sinha, D. K., Murugan, M., Zhu, K. Y., Chen, M. S., Zhu, Y. C., and Smith, C. M. 2014. Comparative gut transcriptome analysis reveals differences between virulent and avirulent Russian wheat aphids, Diuraphis noxia. Arthropod-Plant Interact. 8:79-88.

Atamian, H. S., Chaudhary, R., Dal Cin, V., Bao, E., Girke, T., and Kaloshian, I. 2013. In planta expression or delivery of potato aphid Macrosiphum euphorbiae effectors Me10 and Me23 enhances aphid fecundity. Mol. PlantMicrobe Interact. 26:67-74.

Ausubel, F. M. 2005. Are innate immune signaling pathways in plants and animals conserved? Nat. Immunol. 6:973-979.

Bansal, R., Mian, M. A. R., and Michel, A. P. 2014. Microbiome diversity of Aphis glycines with extensive superinfection in native and invasive populations. Environ. Microbiol. Rep. 6:57-69.

Bokulich, N. A., Kaehler, B. D., Rideout, J. R., Dillon, M., Bolyen, E., Knight, R., Huttley, G. A., and Caporaso, J. G. 2018. Optimizing taxonomic classification of marker gene amplicon sequences. PeerJ Preprints Report No. 2167-9843.

Bos, J. I. B., Prince, D., Pitino, M., Maffei, M. E., Win, J., and Hogenhout, S. A. 2010. A functional genomics approach identifies candidate effectors from the aphid species Myzus persicae (green peach aphid). PLoS Genet. 6:e1001216.

Botha, A. M., Swanevelder, Z. H., and Lapitan, N. L. 2010. Transcript profiling of wheat genes expressed during feeding by two different biotypes of Diuraphis noxia. Environ. Entomol. 39:1206-1231.

Brady, C. L., Cleenwerck, I., Venter, S. N., Engelbeen, K., De Vos, P., and Coutinho, T. A. 2010. Emended description of the genus Pantoea, description of four species from human clinical samples, Pantoea septica sp. nov., Pantoea eucrina sp. nov., Pantoea brenneri sp. nov. and Pantoea conspicua sp. nov., and transfer of Pectobacterium cypripedii (Hori 1911) Brenner et al. 1973 emend. Hauben et al. 1998 to the genus as Pantoea cypripedii comb. nov. Int. J. Syst. Evol. Microbiol. 60:2430-2440.

Brault, V., Tanguy, S., Reinbold, C., Le Trionnaire, G., Arneodo, J., JaubertPossamai, S., Guernec, G., and Tagu, D. 2010. Transcriptomic analysis of intestinal genes following acquisition of pea enation mosaic virus by the pea aphid Acyrthosiphon pisum. J. Gen. Virol. 91:802-808.

Buchner, P. 1965. Endosymbiosis of Animals with Plant Microorganisms. Interscience Publishers, New York.

Burger, N. F. V., and Botha, A. M. 2017. Genome of Russian wheat aphid an economically important cereal aphid. Stand Genomic Sci. 12:90.
Burger, N. F. V., Venter, E., and Botha, A. M. 2017. Profiling Diuraphis noxia (Hemiptera: Aphididae) transcript expression of the biotypes SA1 and SAM feeding on various Triticum aestivum varieties. J. Econ. Entomol. 110: 692-701.

Callahan, B. J., McMurdie, P. J., Rosen, M. J., Han, A. W., Johnson, A. J. A., and Holmes, S. P. 2016. DADA2: High-resolution sample inference from Illumina amplicon data. Nat. Methods 13:581-583.

Campillo, T., Luna, E., Portier, P., Fischer-Le Saux, M., Lapitan, N., Tisserat, N. A., and Leach, J. E. 2015. Erwinia iniecta sp. nov., isolated from Russian wheat aphid (Diuraphis noxia). Int. J. Syst. Evol. Microbiol. 65:3625-3633.

Caporaso, J. G., Kuczynski, J., Stombaugh, J., Bittinger, K., Bushman, F. D., Costello, E. K., Fierer, N., Pena, A. G., Goodrich, J. K., Gordon, J. I., Huttley, G. A., Kelley, S. T., Knights, D., Koenig, J. E., Ley, R. E., Lozupone, C. A., McDonald, D., Muegge, B. D., Pirrung, M., Reeder, J., Sevinsky, J. R., Turnbaugh, P. J., Walters, W. A., Widmann, J., Yatsunenko, T., Zaneveld, J., and Knight, R. 2010. QIIME allows analysis of high-throughput community sequencing data. Nat. Methods 7:335-336.

Capuzzo, C., Firrao, G., Mazzon, L., Squartini, A., and Girolami, V. 2005. 'Candidatus Erwinia dacicola', a coevolved symbiotic bacterium of the olive fly Bactrocera oleae (Gmelin). Int. J. Syst. Evol. Microbiol. 55:1641-1647.

Carolan, J. C., Caragea, D., Reardon, K. T., Mutti, N. S., Dittmer, N., Pappan, K., Cui, F., Castaneto, M., Poulain, J., Dossat, C., Tagu, D., Reese, J. C., Reeck, G. R., Wilkinson, T. L., and Edwards, O. R. 2011. Predicted effector molecules in the salivary secretome of the pea aphid (Acyrthosiphon pisum): A dual transcriptomic/proteomic approach. J. Proteome Res. 10:1505-1518.

Chaudhary, R., Atamian, H. S., Shen, Z., Briggs, S. P., and Kaloshian, I. 2014. GroEL from the endosymbiont Buchnera aphidicola betrays the aphid by triggering plant defense. Proc. Natl. Acad. Sci. USA 111:8919-8924.

Chen, D. Q., and Purcell, A. H. 1997. Occurrence and transmission of facultative endosymbionts in aphids. Curr. Microbiol. 34:220-225.

Chung, S. H., Rosa, C., Scully, E. D., Peiffer, M., Tooker, J. F., Hoover, K., Luthe, D. S., and Felton, G. W. 2013. Herbivore exploits orally secreted bacteria to suppress plant defenses. Proc. Natl. Acad. Sci. USA 110: 15728-15733.

Clark, E., Daniell, T., Wishart, J., Hubbard, S., and Karley, A. 2012. How conserved are the bacterial communities associated with aphids? A detailed assessment of the Brevicoryne brassicae (Hemiptera: Aphididae) using 16S rDNA. Environ. Entomol. 41:1386-1397.

Cooper, W. R., Dillwith, J. W., and Puterka, G. J. 2010. Salivary proteins of Russian wheat aphid (Hemiptera: Aphididae). Environ. Entomol. 39:223-231.

Cooper, W. R., Nicholson, S. J., and Puterka, G. J. 2013. Salivary proteins of Lygus hesperus (Hemiptera: Miridae). Ann. Entomol. Soc. Am. 106:86-92.

Correa, V. R., Majerczak, D. R., Ammar, E.-D., Merighi, M., Pratt, R. C., Hogenhout, S. A., Coplin, D. L., and Redinbaugh, M. G. 2012. The bacterium Pantoea stewartii uses two different type III secretion systems to colonize its plant host and insect vector. Appl. Environ. Microbiol. 78:6327-6336.

Costechareyre, D., Balmand, S., Condemine, G., and Rahbe, Y. 2012. Dickeya dadantii, a plant pathogenic bacterium producing Cyt-like entomotoxins, causes septicemia in the pea aphid Acyrthosiphon pisum. PLoS One 7:e30702.

Ding, L. N., Yang, G. X., Yang, R. Y., Cao, J., and Zhou, Y. 2016. Investigating interactions of salicylic acid and jasmonic acid signaling pathways in monocots wheat. Physiol. Mol. Plant Pathol. 93:67-74.

Douglas, A. E. 1998. Nutritional interactions in insect-microbial symbioses: Aphids and their symbiotic bacteria Buchnera. Annu. Rev. Entomol. 43: 17-37.

Douglas, A. E., and Prosser, W. A. 1992. Synthesis of the essential amino-acid tryptophan in the pea aphid (Acyrthosiphon pisum) symbiosis. J. Insect Physiol. 38:565-568.

Edgar, R. C. 2004. MUSCLE: Multiple sequence alignment with high accuracy and high throughput. Nucleic Acids Res. 32:1792-1797.

Ellers-Kirk, C., and Fleischer, S. J. 2006. Development and life table of Acalymma vittatum (Coleoptera: Chrysomelidae), a vector of Erwinia tracheiphila in cucurbits. Environ. Entomol. 35:875-880.

Elzinga, D. A., De Vos, M., and Jander, G. 2014. Suppression of plant defenses by a Myzus persicae (green peach aphid) salivary effector protein. Mol. PlantMicrobe Interact. 27:747-756.

Elzinga, D. A., and Jander, G. 2013. The role of protein effectors in plant-aphid interactions. Curr. Opin. Plant Biol. 16:451-456.

Estes, A. M., Hearn, D. J., Bronstein, J. L., and Pierson, E. A. 2009. The olive fly endosymbiont, 'Candidatus Erwinia dacicola', switches from an intracellular existence to an extracellular existence during host insect development. Appl. Environ. Microbiol. 75:7097-7106.

Faith, D. P. 1992. Conservation evaluation and phylogenetic diversity. Biol. Conserv. 61:1-10. 
Garcia-Salazar, C., Gildow, F., Fleischer, S., Cox-Foster, D., and Lukezic, F. 2000. ELISA versus immunolocalization to determine the association of Erwinia tracheiphila in Acalymma vittatum (Coleoptera: Chrysomelidae). Environ. Entomol. 29:542-550.

Gauthier, J. P., Outreman, Y., Mieuzet, L., and Simon, J. C. 2015. Bacterial communities associated with host-adapted populations of pea aphids revealed by deep sequencing of $16 \mathrm{~S}$ ribosomal DNA. PLoS One 10: e0120664.

Gil, R., Latorre, A., and Moya, A. 2004. Bacterial endosymbionts of insects: insights from comparative genomics. Environ. Microbiol. 6:1109-1122.

Gitaitis, R., Walcott, R., Wells, M., Perez, J. D., and Sanders, F. 2003. Transmission of Pantoea ananatis, causal agent of center rot of onion, by tobacco thrips, Frankliniella fusca. Plant Dis. 87:675-678.

Halbert, S. E., Mink, G. I., Silbernagel, M. J., and Mowry, T. M. 1994. Transmission of bean common mosaic-virus by cereal aphids (Homoptera, Aphididae). Plant Dis. 78:983-985.

Harada, H., Oyaizu, H., Kosako, Y., and Ishikawa, H. 1997. Erwinia aphidicola, a new species isolated from pea aphid, Acyrthosiphon pisum. J. Gen. Appl. Microbiol. 43:349-354.

Harmel, N., Letocart, E., Cherqui, A., Giordanengo, P., Mazzucchelli, G., Guillonneau, F., De Pauw, E., Haubruge, E., and Francis, F. 2008. Identification of aphid salivary proteins: a proteomic investigation of Myzus persicae. Insect Mol. Biol. 17:165-174.

Hildebrand, M., Dickler, E., and Geider, K. 2000. Occurrence of Erwinia amylovora on insects in a fire blight orchard. J. Phytopathol. 148:251-256.

Holt-Harris, J. E., and Teague, O. 1916. A new culture medium for the isolation of Bacillus typhosus from stools-Plate 20. J. Infect. Dis. 18:596-600.

Jing, X. F., Wong, A. C. N., Chaston, J. M., Colvin, J., McKenzie, C. L., and Douglas, A. E. 2014. The bacterial communities in plant phloem-sap-feeding insects. Mol. Ecol. 23:1433-1444.

Jones, J. D., and Dangl, J. L. 2006. The plant immune system. Nature 444: 323-329.

Jones, R. T., Bressan, A., Greenwell, A. M., and Fierer, N. 2011. Bacterial communities of two parthenogenetic aphid species cocolonizing two host plants across the Hawaiian Islands. Appl. Environ. Microbiol. 77:8345-8349.

Jousselin, E., Clamens, A. L., Galan, M., Bernard, M., Maman, S., Gschloessl, B., Duport, G., Meseguer, A. S., Calevro, F., and Coeur D'Acier, A. 2016. Assessment of a 16S rRNA amplicon Illumina sequencing procedure for studying the microbiome of a symbiont-rich aphid genus. Mol. Ecol. Resour. 16:628-640

Katoh, K., and Standley, D. M. 2013. MAFFT multiple sequence alignment software version 7: Improvements in performance and usability. Mol. Biol. Evol. 30:772-780.

Koga, R., Tsuchida, T., and Fukatsu, T. 2003. Changing partners in an obligate symbiosis: A facultative endosymbiont can compensate for loss of the essential endosymbiont Buchnera in an aphid. Proc. Biol. Sci. 270: 2543-2550.

Koga, R., Tsuchida, T., Sakurai, M., and Fukatsu, T. 2007. Selective elimination of aphid endosymbionts: Effects of antibiotic dose and host genotype, and fitness consequences. FEMS Microbiol. Ecol. 60:229-239.

Langlois, P. A., Snelling, J., Hamilton, J. P., Bragard, C., Koebnik, R., Verdier, V., Triplett, L. R., Blom, J., Tisserat, N. A., and Leach, J. E. 2017. Characterization of the Xanthomonas translucens complex using draft genomes, comparative genomics, phylogenetic analysis, and diagnostic LAMP assays. Phytopathology 107:519-527.

Lindman, H. R. 2012. Analysis of Variance in Experimental Design. SpringerVerlag, New York.

Martinec, T., and Kocur, M. 1964. A taxonomic study of Erwinia amylovora (Burrill 1882) Winslow Et Al 1920. Int. Bull. Bacteriol. Nomencl. Taxon. 14: 5-14.

Miles, P. W. 1999. Aphid saliva. Biol. Rev. Camb. Philos. Soc. 74:41-85.

Montllor, C. B., Maxmen, A., and Purcell, A. H. 2002. Facultative bacterial endosymbionts benefit pea aphids Acyrthosiphon pisum under heat stress. Ecol. Entomol. 27:189-195.

Moran, N. A., Munson, M. A., Baumann, P., and Ishikawa, H. 1993. A molecular clock in endosymbiotic bacteria is calibrated using the insect hosts. Proc. Roy. Soc. B-Biol. Sci. 253:167-171.

Mugford, S. T., Barclay, E., Drurey, C., Findlay, K. C., and Hogenhout, S. A. 2016. An immuno-suppressive aphid saliva protein is delivered into the cytosol of plant mesophyll cells curing feeding. Mol. Plant-Microbe Interact. 29:854-861.

Nesvizhskii, A. I., Keller, A., Kolker, E., and Aebersold, R. 2003. A statistical model for identifying proteins by tandem mass spectrometry. Anal. Chem. 75: 4646-4658.
Nicholson, S. J., Hartson, S. D., and Puterka, G. J. 2012. Proteomic analysis of secreted saliva from Russian wheat aphid (Diuraphis noxia Kurd.) biotypes that differ in virulence to wheat. J. Proteomics 75:2252-2268.

Nicholson, S. J., Nickerson, M. L., Dean, M., Song, Y., Hoyt, P. R., Rhee, H., Kim, C., and Puterka, G. J. 2015. The genome of Diuraphis noxia, a global aphid pest of small grains. BMC Genomics 16:429.

Nicholson, S. J., and Puterka, G. J. 2014. Variation in the salivary proteomes of differentially virulent greenbug (Schizaphis graminum Rondani) biotypes. J. Proteomics 105:186-203.

Oliver, K. M., Degnan, P. H., Burke, G. R., and Moran, N. A. 2010. Facultative symbionts in aphids and the horizontal transfer of ecologically important traits. Annu. Rev. Entomol. 55:247-266.

Oliver, K. M., Noge, K., Huang, E. M., Campos, J. M., Becerra, J. X., and Hunter, M. S. 2012. Parasitic wasp responses to symbiont-based defense in aphids. BMC Biol. 10:11.

Oliver, K. M., Russell, J. A., Moran, N. A., and Hunter, M. S. 2003. Facultative bacterial symbionts in aphids confer resistance to parasitic wasps. Proc. Natl. Acad. Sci. USA 100:1803-1807.

Pan, X., Welti, R., and Wang, X. 2010. Quantitative analysis of major plant hormones in crude plant extracts by high-performance liquid chromatography-mass spectrometry. Nat. Protoc. 5:986-992.

Plurad, S., Goodman, R., and Enns, W. 1965. Persistence of Erwinia amylovora in the apple aphid (Aphis pomi DeGeer), a probable vector. Nature 205:206.

Price, M. N., Dehal, P. S., and Arkin, A. P. 2010. FastTree 2-approximately maximum-likelihood trees for large alignments. PLoS One 5:e9490.

Pruesse, E., Peplies, J., and Glockner, F. O. 2012. SINA: Accurate highthroughput multiple sequence alignment of ribosomal RNA genes. Bioinformatics 28:1823-1829.

Ramsey, J. S., Johnson, R. S., Hoki, J. S., Kruse, A., Mahoney, J., Hilf, M. E., Hunter, W. B., Hall, D. G., Schroeder, F. C., MacCoss, M. J., and Cilia, M. 2015. Metabolic interplay between the Asian citrus psyllid and its profftella symbiont: An Achilles' heel of the citrus greening insect vector. PLoS One 10:e0140826.

Randolph, T. L., Peairs, F., Weiland, A., Rudolph, J. B., and Puterka, G. J. 2009. Plant responses to seven Russian wheat aphid (Hemiptera: Aphididae) biotypes found in the United States. J. Econ. Entomol. 102:1954-1959.

Rao, S. A. K., Carolan, J. C., and Wilkinson, T. L. 2013. Proteomic profiling of cereal aphid saliva reveals both ubiquitous and adaptive secreted proteins. PLoS One 8:e57413.

Reimers, P. J., and Leach, J. E. 1991. Race-specific resistance to Xanthomonas oryzae pv. oryzae conferred by bacterial-blight resistance gene $\mathrm{Xa}-10$ in rice (Oryza sativa) involves accumulation of a lignin-like substance in host tissues. Physiol. Mol. Plant Pathol. 38:39-55.

Rodriguez, P. A., and Bos, J. I. B. 2013. Toward understanding the role of aphid effectors in plant infestation. Mol. Plant-Microbe Interact. 26:25-30.

Scarborough, C. L., Ferrari, J., and Godfray, H. C. J. 2005. Aphid protected from pathogen by endosymbiont. Science 310:1781.

Schliep, K. P. 2011. phangorn: Phylogenetic analysis in R. Bioinformatics 27: 592-593.

Schneider, C. A., Rasband, W. S., and Eliceiri, K. W. 2012. NIH Image to ImageJ: 25 years of image analysis. Nat. Methods 9:671-675.

Schwartzberg, E. G., and Tumlinson, J. H. 2014. Aphid honeydew alters plant defense responses. Funct. Ecol. 28:386-394.

Scuoppo, C., Miething, C., Lindqvist, L., Reyes, J., Ruse, C., Appelmann, I., Yoon, S., Krasnitz, A., Teruya-Feldstein, J., Pappin, D., Pelletier, J., and Lowe, S. W. 2012. A tumour suppressor network relying on the polyaminehypusine axis. Nature 487:244-248.

Shadforth, I. P., Dunkley, T. P., Lilley, K. S., and Bessant, C. 2005. i-Tracker: For quantitative proteomics using iTRAQ. BMC Genomics 6:145.

Skrodenytė-Arbačiauskienè, V., Radžiutè, S., Stunžènas, V., and Būda, V. 2012. Erwinia typographi sp. nov., isolated from bark beetle (Ips typographus) gut. Int. J. Syst. Evol. Microbiol. 62:942-948.

Stavrinides, J., McCloskey, J. K., and Ochman, H. 2009. Pea aphid as both host and vector for the phytopathogenic bacterium Pseudomonas syringae. Appl. Environ. Microbiol. 75:2230-2235.

Stavrinides, J., No, A., and Ochman, H. 2010. A single genetic locus in the phytopathogen Pantoea stewartii enables gut colonization and pathogenicity in an insect host. Environ. Microbiol. 12:147-155.

Su, Q., Oliver, K. M., Xie, W., Wu, Q. J., Wang, S. L., and Zhang, Y. J. 2015. The whitefly-associated facultative symbiont Hamiltonella defensa suppresses induced plant defences in tomato. Funct. Ecol. 29:1007-1018.

Summers, C. G., Newton, A. S., Kirk, M., and Temple, S. R. 1990. Transmission of beet yellows and beet mosaic-viruses by noncolonizing aphid vectors. J. Econ. Entomol. 83:2448-2451. 
Taylor, P., Nielsen, P. A., Trelle, M. B., Horning, O. B., Andersen, M. B., Vorm, O., Moran, M. F., and Kislinger, T. 2009. Automated 2D peptide separation on a 1D nano-LC-MS system. J. Proteome Res. 8:1610-1616.

Thaler, J. S., Humphrey, P. T., and Whiteman, N. K. 2012. Evolution of jasmonate and salicylate signal crosstalk. Trends Plant Sci. 17:260-270.

Vandermoten, S., Harmel, N., Mazzucchelli, G., De Pauw, E., Haubruge, E., and Francis, F. 2014. Comparative analyses of salivary proteins from three aphid species. Insect Mol. Biol. 23:67-77.

Washburn, M. P. 2004. Utilisation of proteomics datasets generated via multidimensional protein identification technology (MudPIT). Brief. Funct. Genomics Proteomics 3:280-286.

Watson, B. S., Bedair, M. F., Urbanczyk-Wochniak, E., Huhman, D. V., Yang, D. S., Allen, S. N., Li, W., Tang, Y., and Sumner, L. W. 2015. Integrated metabolomics and transcriptomics reveal enhanced specialized metabolism in Medicago truncatula root border cells. Plant Physiol. 167:1699-1716.

Webster, J. A., Starks, K. J., and Burton, R. L. 1987. Plant-resistance studies with Diuraphis noxia (Homoptera, Aphididae), a new United States wheat pest. J. Econ. Entomol. 80:944-949.

Weisburg, W. G., Barns, S. M., Pelletier, D. A., and Lane, D. J. 1991. 16S ribosomal DNA amplification for phylogenetic study. J. Bacteriol. 173:697-703. Wells, M., Gitaitis, R., and Sanders, F. 2002. Association of tobacco thrips, Frankliniella fusca (Thysanoptera: Thripidae) with two species of bacteria of the genus Pantoea. Ann. Entomol. Soc. Am. 95:719-723.

Zwer, P. K., Mosaad, M. G., Elsidaig, A. A., and Rickman, R. W. 1994. Effect of Russian wheat aphid on wheat root and shoot development in resistant and susceptible genotypes. Crop Sci. 34:650-655. 